\title{
Diffusion of surface-active amphiphiles in silicone-based fouling-release coatings
}

\author{
Noguer, Albert Camós; Olsen, S. M.; Hvilsted, Søren; Kiil, Søren
}

Published in:

Progress in Organic Coatings

Link to article, DOI:

10.1016/j.porgcoat.2017.02.014

Publication date:

2017

Document Version

Peer reviewed version

Link back to DTU Orbit

Citation (APA):

Noguer, A. C., Olsen, S. M., Hvilsted, S., \& Kiil, S. (2017). Diffusion of surface-active amphiphiles in siliconebased fouling-release coatings. Progress in Organic Coatings, 106, 77-86.

https://doi.org/10.1016/j.porgcoat.2017.02.014

\section{General rights}

Copyright and moral rights for the publications made accessible in the public portal are retained by the authors and/or other copyright owners and it is a condition of accessing publications that users recognise and abide by the legal requirements associated with these rights.

- Users may download and print one copy of any publication from the public portal for the purpose of private study or research.

- You may not further distribute the material or use it for any profit-making activity or commercial gain

- You may freely distribute the URL identifying the publication in the public portal

If you believe that this document breaches copyright please contact us providing details, and we will remove access to the work immediately and investigate your claim 


\section{Diffusion of surface-active}

\section{amphiphiles in silicone-based fouling-}

\section{release coatings}

A. Camós Noguera,b, S. M. Olsen ${ }^{b}$, S. Hvilsted ${ }^{a}$, S. Kiila,*

a

Department of Chemical and Biochemical Engineering, Technical University of Denmark (DTU), Building 229, 2800 Kgs. Lyngby, Denmark

email: alno@kt.dtu.dk

telephone: +45 45252829

b

Department of Fouling Release Systems, Hempel A/S, Lundtoftegårdsvej 91, 2800 Kgs. Lyngby,

Denmark

email: stmo@hempel.com

telephone: +45 45933800

*Corresponding author, e-mail adress: sk@kt.dtu.dk, telephone: +45 45252827 (Søren Kiil)

\section{Abstract}

Amphiphiles (i.e. amphiphilic molecules such as surfactants, block copolymers and similar compounds) are used in small amounts to modify the surface properties of polymeric materials. In silicone foulingrelease coatings, PEG-based amphiphiles are added to provide biofouling-resistance. The success of this approach relies on the ability of the amphiphiles to diffuse through the coating film and cover the surface of the coating.

A novel method for the measurement of diffusion coefficients of PEG-based amphiphiles of different chemistries in PDMS-based coatings is presented here. The diffusion coefficient of the amphiphiles shows a weak dependency on their molecular weight, although this dependency is much less 
pronounced than for other rubbery polymeric materials. The biofouling-resistance properties in foulingrelease coatings were also studied for these amphiphiles. It was found that the diffusion coefficient does not have any influence on the biofouling-resistance results for the studied compounds. Instead, the chemistry of the hydrophobic block of the amphiphiles is much more significant, with PEG-PDMS block copolymers showing the best properties among the studied compounds.

\title{
Highlights
}

A method to measure diffusion coefficients of amphiphiles in PDMS films is presented.

PEG-based amphiphiles used in PDMS coatings migrate to the coating surface.

The relationship between the diffusion coefficient and fouling-resistance is studied.

Fouling-resistance is strongly dependent on the chemistry of hydrophobic block.

\section{Keywords}

Diffusion; block copolymers; amphiphiles; biofouling; fouling-release coatings

\section{Nomenclature}

\author{
PBDE Polybrominated biphenyl ethers \\ PCB Polychlorinated biphenyl \\ PDMS Polydimethylsiloxane \\ PEG Poly(ethylene glycol) \\ PET Poly(ethylene terephthalate) \\ PMMA Poly(methyl methacrylate) \\ PP Polypropylene \\ PPG Poly(propylene glycol) \\ SDS Sodium dodecyl sulfonate \\ SEC Size exclusion chromatography \\ SLS Sodium lauryl sulphate
}




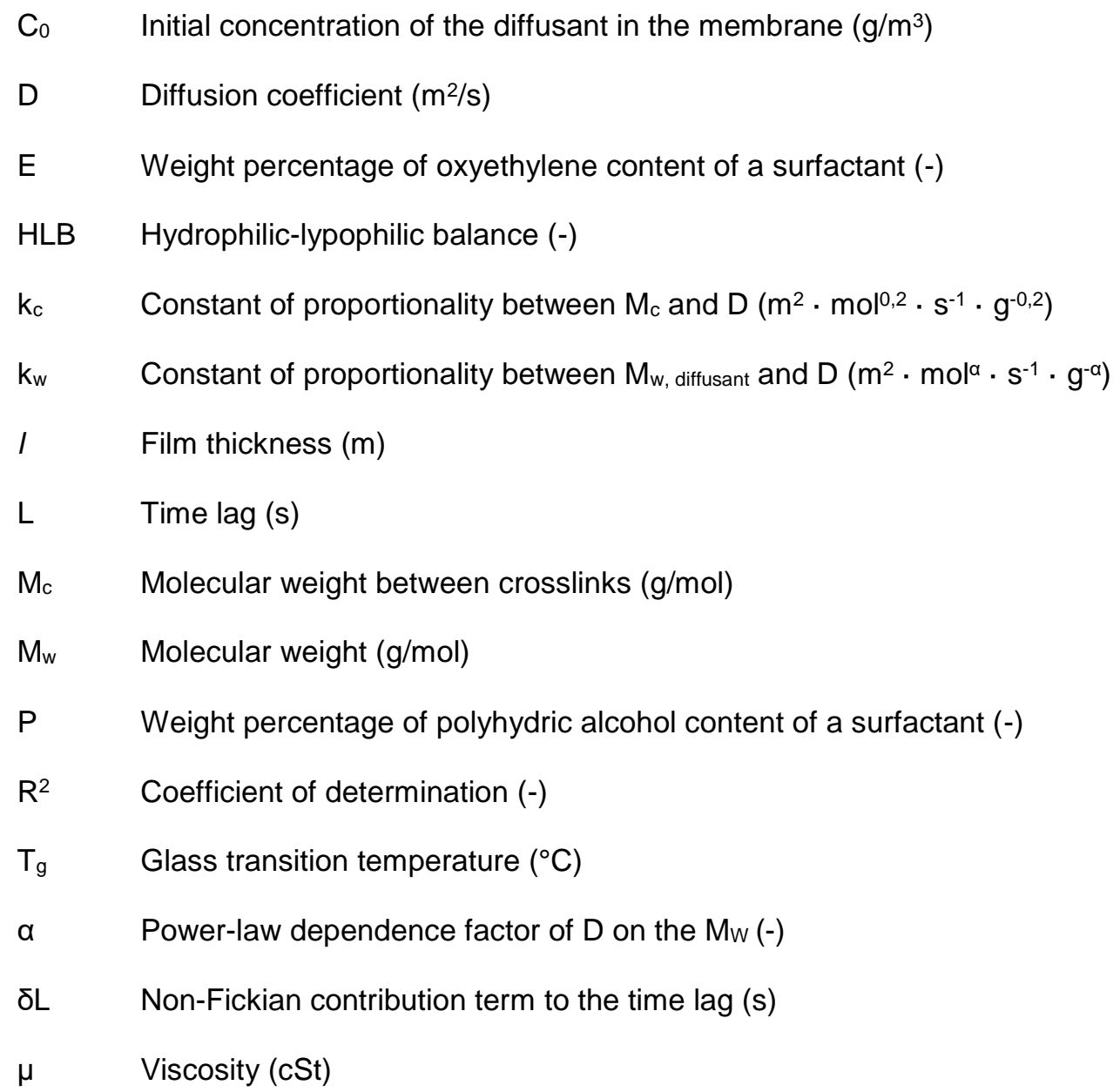

\section{Introduction}

Additives are usually used to modify the processing and final properties of polymeric materials. Plasticizers, antioxidants and flame retardants are examples of such additives [1]. The use of surfaceactive additives has gained interest as an easy, cheap and fast way to modify the surface properties of polymeric materials. These surface-active compounds (usually block copolymers) migrate to the material surface and cover it, thus significantly changing the surface properties of the material with a very small impact on its bulk properties [2,3]. For example, James et al. [4] added a fluoro-modified polystyrene additive to a polyester to improve its stability against hydrolysis. Miyata et al. [5] added polydimethylsiloxane- (PDMS) based copolymer additives to a PDMS membrane in order to improve the ethanol permeation selectivity of the membrane. Likewise, Wu and Hjort [6] added triblock poly(ethylene glycol)-poly(propylene glycol)-poly(ethylene glycol) (PEG-PPG-PEG) copolymers to PDMS to supress nonspecific protein adsorption on the surface of microfluidic devices. Furthermore, Røn et al. [7] used poly(acrylic acid)- and poly(ethylene glycol)-based block copolymers to improve the 
lubricity of PDMS surfaces. In the field of coatings, surface-active additives have been employed for a range of purposes: as stabilizing agents for single-wall carbon nanotubes [8] and for bactericidal silver ion delivery in polyurethane-based coatings [9]. Moreover, they have been used to increase the colloidal stability in emulsion polymerization for latex coatings [10] and to improve the flowing and levelling properties of polyurethane coatings [11] to mention some examples.

Irrespective of the intended use of these surface-active compounds, they have a tendency to diffuse and migrate to interfaces [3]. Siloxane additives used as flow agents migrate to the surface of automotive clearcoats, compromising the adhesion of pressure-sensitive adhesives on the clearcoats [12], and it has been reported [13] that the surfactants used in latex-based coatings can exudate to the interfaces of the latex film, giving rise to optical and adhesion problems. On the other hand, the diffusion of surfaceactive additives to the coatings' interfaces has beneficial effects in other cases. Polyfluorinated surfactants have been used in coatings for food packaging to provide water and oil repellency [14]. Similarly, Rixens et al. [15] used phosponic ester- and phosphonic acid-modified polymers to increase the adhesion of vinylidene chloride-methyl acrylate coatings on metal substrates. Moreover, PEG-based copolymers have been used as additives for PDMS-based fouling-release coatings to decrease biofouling and barnacle adhesion [16].

Biofouling is the undesired accumulation of organisms on immersed surfaces such as biomedical implants, biosensors and ships [17]. The use of different kinds of surface-active compounds to decrease the amount of biofouling on fouling-release coatings is widespread. Various patents [18-24] and articles $[2,25-28]$ in the field describe the use of both reactive and non-reactive amphiphilic copolymers in fouling-release coatings, mainly based on fluorinated, siloxane and oxyalkylane moieties. Among them, poly(ethylene glycol) has shown promising results in the biomedical field regarding fouling-resistance properties [29]. Different methods have been used to functionalize surfaces with PEG. Besides adding PEG-based surface-active compounds to change the surface properties of PDMS films, PEG has also been covalently grafted or physically adsorbed on different substrates $[29,30]$. However, these methods are more expensive and are not applicable for big-scale productions like fouling-release coatings for ships. Therefore, it is believed that incorporating PEG-based copolymers and exploiting their surfaceactivity is the most effective way to obtain long-term effective fouling-release coatings. The proposed working mechanism for these additives is based on the segregation and coverage of the coating surface. The driving force leading to the surface segregation of different kinds of polymer additives has been 
previously studied. Inutsuka et al. [31] investigated the segregation of PDMS-b-PEG copolymers in PDMS films under water. The migration driving force was attributed to the enthalpic gain associated with the solvation of the PEG block of the copolymer molecules at the film surface. Lee and Archer $[3,32]$ studied the segregation of different additives in polystyrene (PS) hosts, and similarly found the decrease in the system's energy one of the main driving forces. Regarding the covering of the coating surface, the hydrophobic block of the copolymer acts as an anchor on the surface, while the PEG block provides the fouling-release protection $[33,34]$. Therefore, the long-term fouling-release protection properties of these coatings are dictated both by the hydrophobic and the hydrophilic blocks of these amphiphilic additives.

The characterization of surface segregation/enrichment in polymeric materials has been achieved by different means. Radioactive labelling [35], infrared microdensiometry [35], fluorescence tracing [36], time-of-flight secondary ion mass spectrometry (ToF-SIMS) [37] and X-ray photoelectron spectroscopy (XPS) [38] have been used with successful results. Similarly, the diffusion of different migrants in polymer hosts has also been studied by methods such as Raman spectroscopy [39], gas chromatography (GC) [39] and infrared spectroscopy (IR) [40] among others.

In this paper, the functionalization of silicone-based fouling-release coatings by addition of PEG-based amphiphiles is studied. An amphiphile is a molecule having different blocks, which provide both hydrophobic and hydrophilic properties to the molecule. Amphiphiles with three different kinds of hydrophobic blocks have been used, while PEG has been kept as hydrophilic block for all of them. The three hydrophobic blocks chosen have been: (1) alkyl hydrocarbon chains, (2) alkyl hydrocarbon chains connected to an aryl group and (3) PDMS chains, with different molecular weight and structure. A new procedure, based on a time lag method combined with an optical tensiometer, is used to study the diffusion of these amphiphiles through crosslinked PDMS films for fouling-release purposes. The use of time lag methods has previously been reported in the literature to obtain diffusion coefficients of different compounds in films. For example, Stewart et al [41] measured the diffusivity of acids through thin polymer films below and above the glass transition temperature $\left(T_{g}\right)$. Valente et al. [42], studied the diffusion of sodium dodecyl sulphate (SDS) through cellulose esters membranes, and Faucher et al. [43] analysed diffusion phenomena of sodium lauryl sulphate (SLS) through rat stratum corneum. In contrast with other methods that usually require sample preparation, extraction methods, vacuum and/or long waiting times, diffusion coefficients for relatively high molecular weight $\left(\mathrm{M}_{\mathrm{w}}\right)$ amphiphiles and block 
copolymers can be obtained in an easy and rapid way by using the method presented in this work. Experimental diffusion coefficients are obtained for such molecules in crosslinked PDMS films. In addition, the diffusion coefficients obtained are compared to literature values of other diffusing molecules and polymers. The effect of the diffusant chemistry and $M_{w}$ on the diffusion of these compounds within the coating film and the influence on the final fouling-resistance properties of the coatings are discussed.

\section{Materials and Methods}

\section{$\underline{2.1 \text { Materials }}$}

Silanol terminated PDMS (4000 cSt) was received from Dow Corning and vinyl tris(methyl ethyl ketoxime) silane from Evonik. Fumed silica Aerosil R8200 was received from Evonik and red iron oxide pigment Bayferrox 130M from Lanxess.

PEG400, Brij O10, Brij O20, Triton X-100, Igepal CO-720 and Tween 85 were obtained from SigmaAldrich. Sapogenat T 080 and Sapogenat T 130 were received from Clariant. Lumulse POE(7) GML was received from Lambent Corp, Serdox NES 7 from Elementis Specialities and PEG 12 stearate from A\&E Connock. The three PDMS-PEG copolymers analysed (copolymer 1, copolymer 2 and copolymer 3) were obtained from Dow Corning, Evonik and Siltech Corp. The chemical properties of the abovementioned compounds can be found in Table 1.

All the materials were used as received without further purification. 
Table 1. Chemical composition and properties of the amphiphiles used and the diffusion coefficients obtained. Structure (where A represents the hydrophilic block and B the hydrophobic block), molecular weight $\left(\mathrm{M}_{\mathrm{w}}\right)$, number of poly(ethylene glycol) (PEG) units, hydrophilic-lipophilic balance (HLB) and diffusion coefficient (D) are shown for each amphiphile. Note that they have been ordered according to the chemistry of the hydrophobic block of the amphiphile.

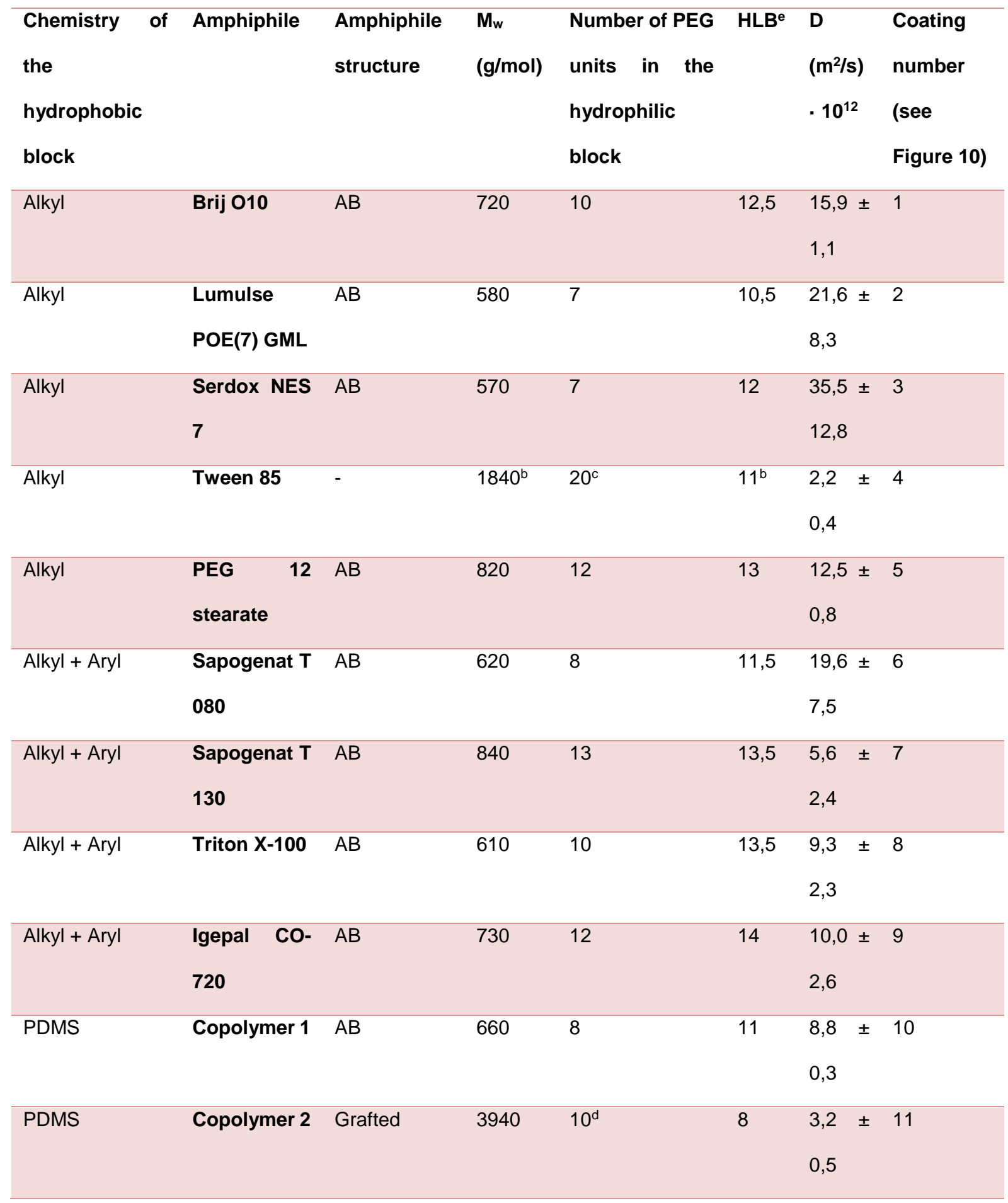




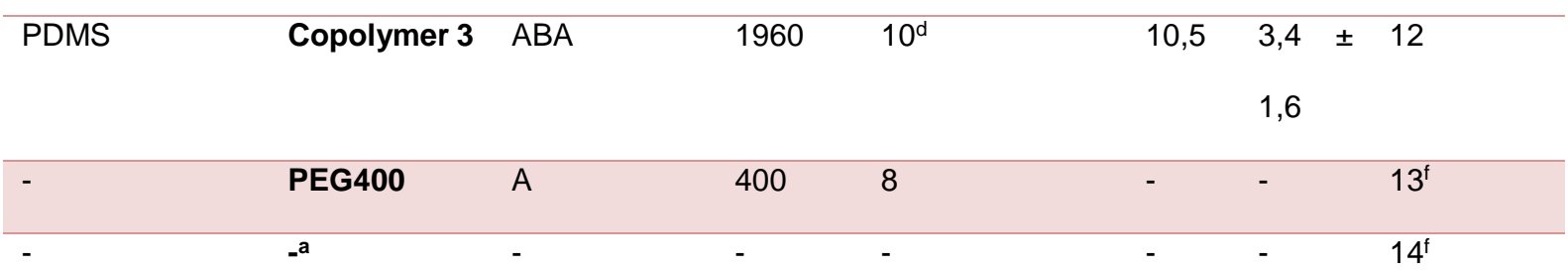

a No additive was used for this coating

b The value provided by the supplier was used

${ }^{c}$ Total number of PEG units in the molecule, distributed in 4 different branches

d Number of PEG units in each block/branch

e Estimated using Equation 4

${ }^{\dagger}$ Coatings only used as references for contact angle and static immersion tests

\section{$\underline{2.2 \text { Preparation of coatings }}$}

The amphiphiles listed in Table 1 were added as additives to conventional silicone (PDMS) coatings. The coatings were prepared by mixing silanol terminated PDMS with a trifunctional oximinosilane crosslinker (vinyl tris(methyl ethyl ketoxime) silane) using xylene as solvent. Iron oxide Bayferrox 130M was added as red pigment so it accounted for $5 \%$ of the dry weight of the film. Surface treated fumed silica Aerosil R8200 was added so it accounted for $1 \%$ of the final weight of the film. The pigment and the silica were premixed with the PDMS binder in a pearl mill for 1 hour. The amphiphiles in Table 1 were added so they accounted for $4 \%$ of the total weight in the dry film. The mixtures were applied on glass slides substrates $(2.5 \times 7.5 \mathrm{~cm})$ using a $6 \mathrm{~cm}$ Dr Blade applicator with a $400 \mu \mathrm{m}$ gap and cured for a week at room temperature. These coatings were used for the study of the diffusion coefficients.

The mixtures were also applied on poly(methyl methacrylate) (PMMA) substrates $(10 \times 20 \mathrm{~cm})$ using a $8 \mathrm{~cm}$ Dr Blade applicator with a $400 \mu \mathrm{m}$ gap and cured for a week at room temperature. Then, the top half-part of the panel was protected with aluminium foil, and the bottom part was covered (spray-applied) with an additive-free PDMS coating (coating 14 in Table 1). The wet thickness applied was approximately $350 \mu \mathrm{m}$, and the panels were cured for a week at room temperature. These coatings were used to study the diffusion and fouling-resistance properties of the additives (see Figure 1). Note that all 
the analysed coatings were biocide-free, i.e., the protection against biofouling was solely provided by the amphiphilic additives investigated and the physico-chemical properties of the PDMS surface.

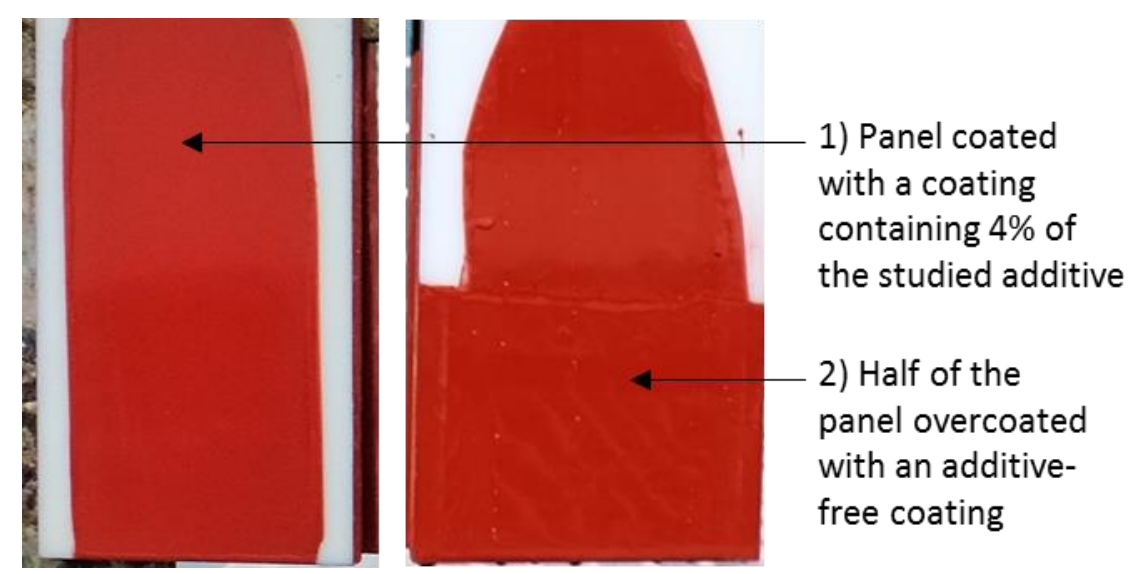

Figure 1. Preparation of the coatings for seawater exposure, with two layers. The first layer consisted of a coating containing $4 \mathrm{wt} \%$ of the studied amphiphiles, and half of the cured coating was overcoated with a layer of an additive-free coating.

Free-film coatings were applied using a $15 \mathrm{~cm}$ Dr Blade applicator with different gap size on poly(ethylene terephthalate) (PET) substrates, and cured for a week at room temperature. These coatings did not contain any of the studied amphiphiles (see coating 14 in Table 1). Three different thicknesses were applied, and the thickness of the final dry films were measured by use of optical microscopy. The coatings were cut with a scalpel and the cross-section of the coatings was analysed in the optical microscope. The measured thicknesses were $l_{1}=85 \pm 2 \mu \mathrm{m}, \mathrm{l}_{2}=132 \pm 3 \mu \mathrm{m}$ and $\mathrm{l}_{3}=168 \pm$ $16 \mu \mathrm{m}$ (average of three measurements). These films were used as "membranes" to study the diffusion coefficients of the different PEG-based amphiphiles, as explained in the following sections.

\subsection{Molecular weight measurements}

The molecular weight of the different amphiphiles used can be found in Table 1. The molecular weights reported are based on Size Exclusion Chromatography (SEC) measurements calibrated with PEG standards. The molecular weight values obtained were compared with those provided by the suppliers, when available, showing differences below $5 \%$. The only exception was Tween 85 , which showed a large difference, probably due to the highly branched structure of this amphiphile. Therefore, the $\mathrm{Mw}_{\mathrm{w}}$ value provided by the supplier has been used for this compound. 
The molecular weight of the silanol terminated PDMS used as binder was determined based on its viscosity. By using Equation 1, proposed by Barry [44] in 1950, it was estimated that the molecular weight of the PDMS binder used was $45000 \mathrm{~g} / \mathrm{mol}$, significantly higher than the molecular weight of the studied amphiphiles. Note that for this kind of networks, the molecular weight between crosslinks $\left(M_{c}\right)$ coincides with the molecular weight of the binder, and is sometimes referred to as the "molecular weight of the network". The molecular weight between crosslinks $\left(M_{c}\right)$ was kept constant throughout all the experiments.

$$
\log \mu=1+0,0123 \cdot M_{w}^{1 / 2}
$$

(Equation 1)

In Equation $1, \mu$ is the viscosity of the polymer in cSt $\left(1 \mathrm{cSt}=10^{-6} \mathrm{~m}^{2} / \mathrm{s}\right)$, and $\mathrm{M}_{\mathrm{w}}$ is the molecular weight of the polymer in $\mathrm{g} / \mathrm{mol}$.

\subsection{The time lag method}

The time lag method presented here is inspired by a methodology that was first developed by H. A. Daynes [45] in 1920, in studies of the diffusion of gases through rubber membranes. The method allowed calculation of diffusion and permeability coefficients for systems following Fick's diffusion law with negligible resistance at the interfaces. In those experiments, one side of a rubber membrane, of thickness I, was exposed to a gas (e.g. hydrogen) while the amount of gas released on the other side of the membrane was monitored by a katharometer. It was found that after a period where no gas was detected, the so-called time lag, the concentration of the gas started increasing at a constant rate (see Figure 2a). 
a)

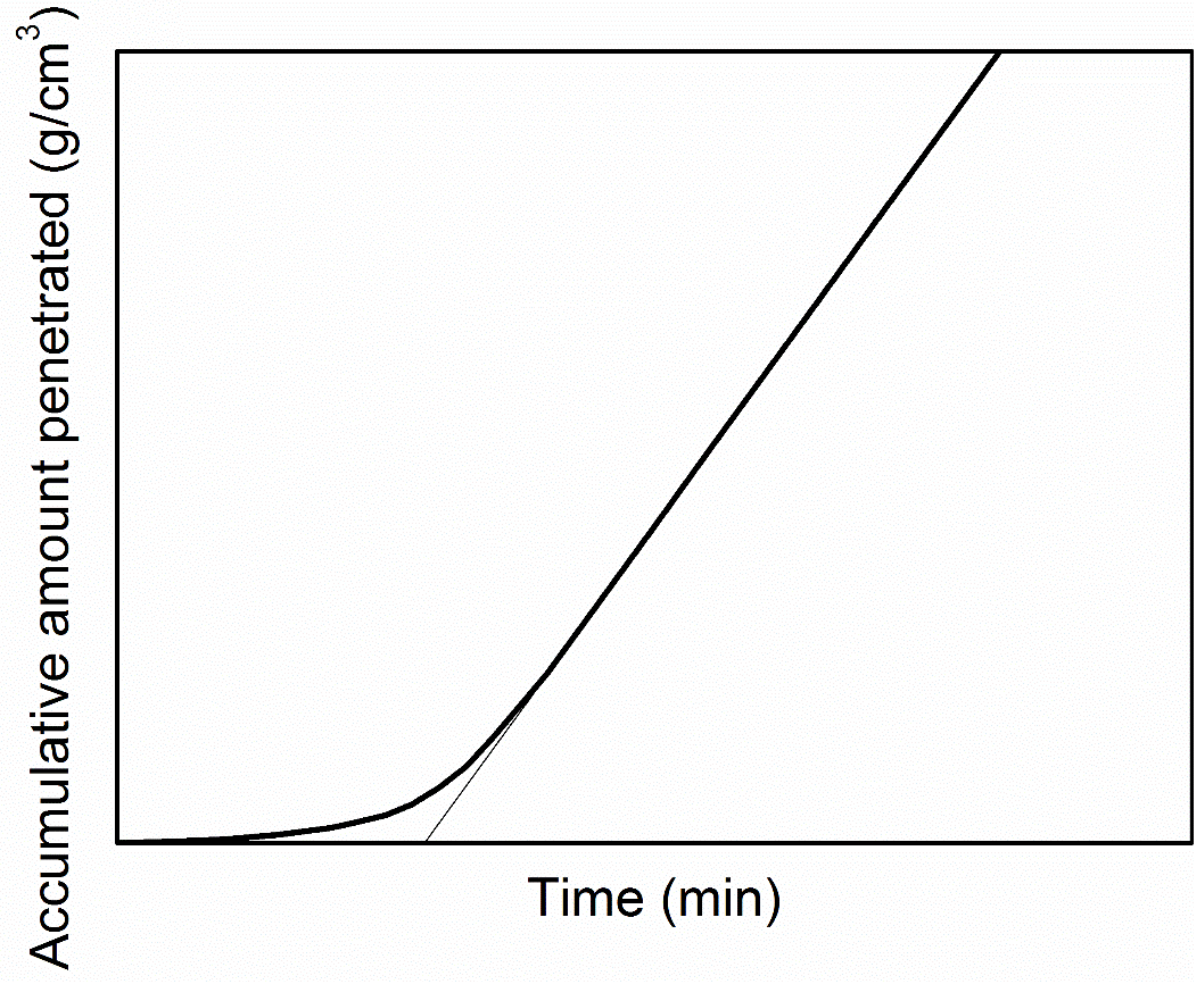

b)

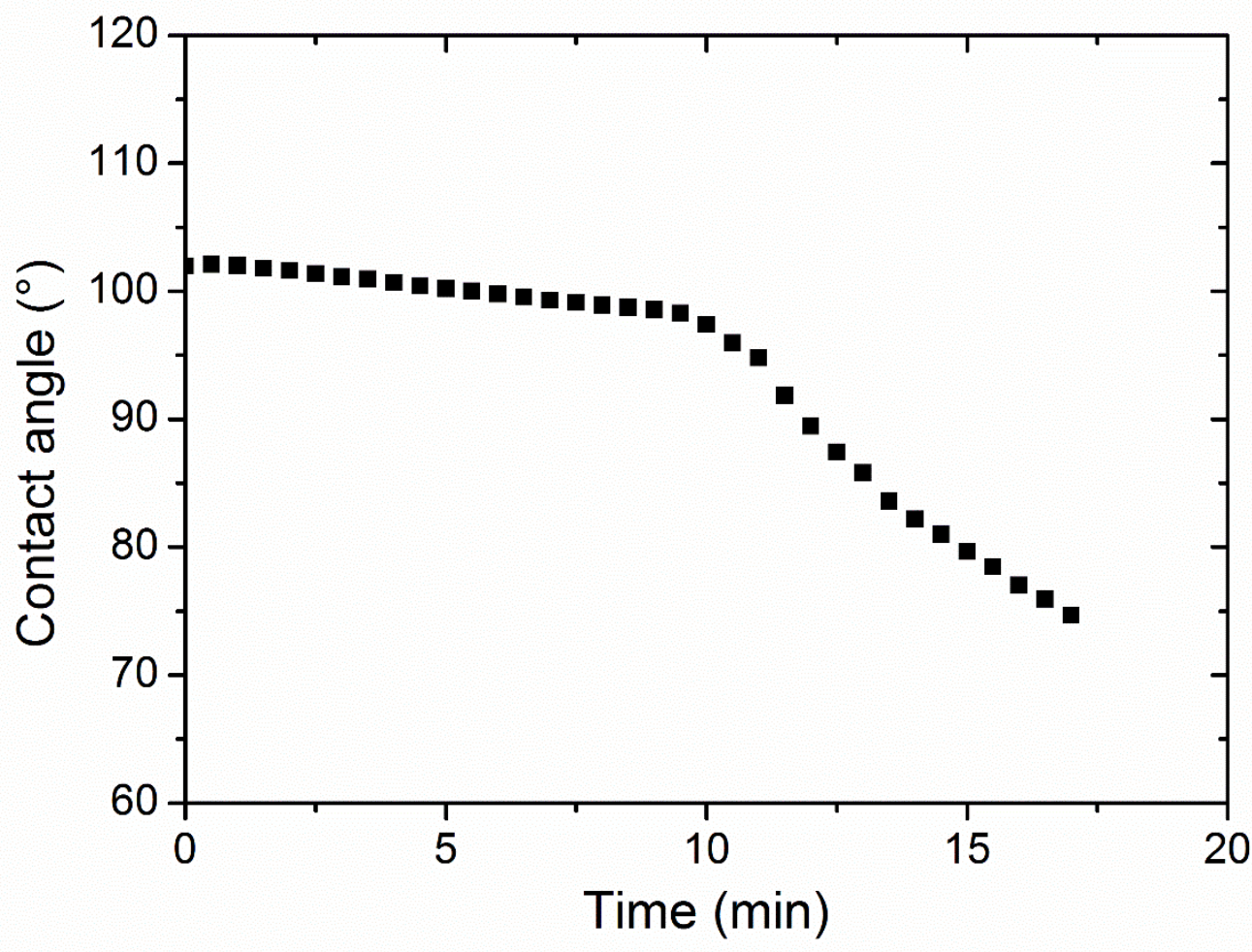


Figure 2. Example of results obtained with (a) original time lag method by Daynes [45] and (b) with the presented set-up.

Figure 3 shows a scheme of the setup used in this work. The original rubber membrane in the works of H. A. Daynes [45] was replaced by an additive-free PDMS coating (film). The concentration gradient of diffusant was now provided by, on one side, a PDMS film containing 4 wt $\%$ of the studied amphiphile, while a droplet of fresh water was placed on the other. To asses the presence of diffusant on the second interface, a tensiometer was used to monitor the contact angle of the water droplet. It is well-known that the presence of a surface-active additive in PDMS results in a change on the properties of the surface and, therefore, the contact angle changes [46]. An example of the results obtained by this method can be seen in Figure $2 b$, where the contact angle is plotted over time. A lag time can clearly be identified, after which the contact angle drops due to the presence of the amphiphile. This change in slope is used here to identify the time lag L.
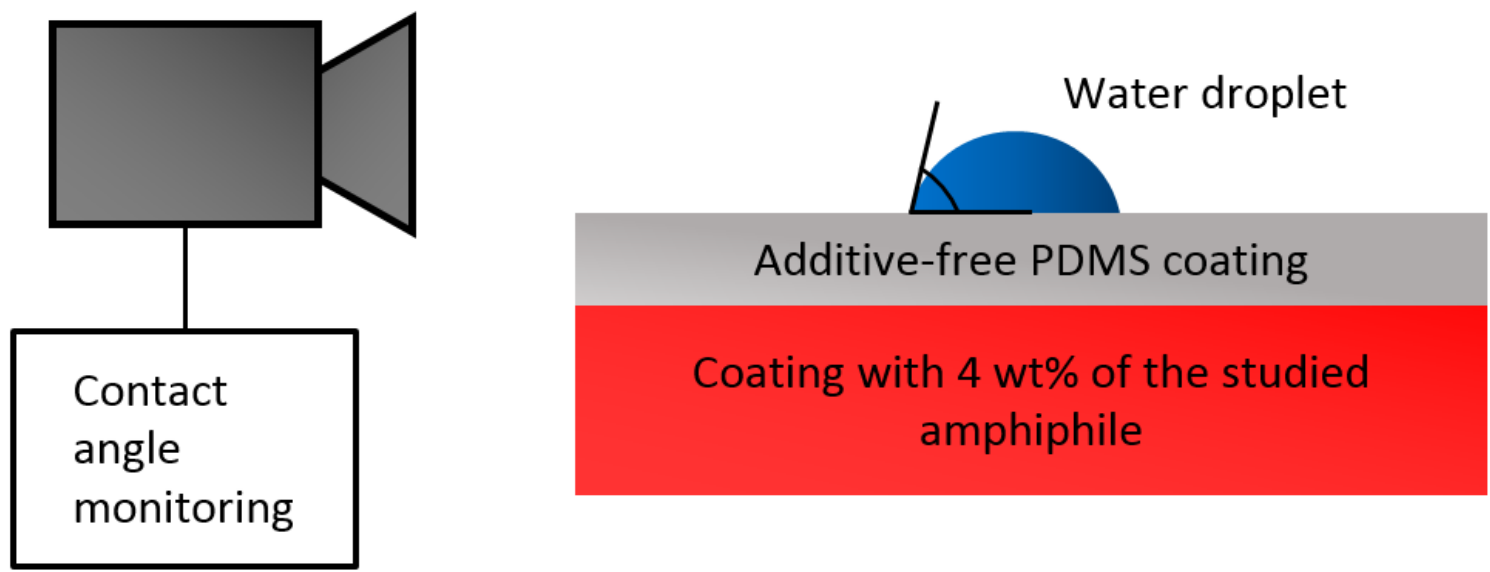

Figure 3. Outline of the modified time lag method used for the measurement of diffusion coefficients. An additive-free PDMS coating is placed as "membrane" between a coating containing the studied amphiphile and a water droplet. The contact angle is monitored and the time lag, $\mathrm{L}$, is obtained.

Assuming that the diffusion coefficient is independent of the thickness of the membrane, the concentration of the diffusant and time, Fick's law can be solved for that system. It has been shown [45] that the diffusion coefficient can be calculated from the time lag value through Equation 2:

$$
L=\frac{l^{2}}{6 D}
$$


(Equation 2)

where $L$ is the time lag in $s, I$ is the thickness of the membrane in $m$ and $D$ is the diffusion coefficient in $\mathrm{m}^{2} / \mathrm{s}$

Later, this model was extended to other geometries and cases, such as when the diffusion coefficient is dependent on the concentration or when there is an initial concentration $\mathrm{C}_{0}$ of diffusant in the membrane, to mention some examples $[47,48]$.

However, different cases have been reported to differ from the conditions/assumptions that led to Equation 2: systems with non-negligible entry resistance at the interfaces of the membrane and timedependent diffusion coefficients [49,50]. Likewise, polymer membranes near or below their glass transition temperature show much larger relaxation times, having a strong influence on the diffusion processes hosted $[51,52]$. Some authors have referred to these deviations as "non-Fickian anomalies" and have added a term, $\delta \mathrm{L}$, to Equation 2 to account for these anomalies [49,51] (see Equation 3). Others, however, defend that the addition of this term is not necessary and that all these "non-Fickian anomalies" can in fact be described by Fick's diffusion law if the proper boundary conditions are used [53].

$$
L=\frac{l^{2}}{6 D}+\delta L
$$

(Equation 3)

By assuming that the term $\delta L$ is independent of the thickness of the membrane, a plot of $L$ vs $R$ can be used to obtain D coefficients, while an ordinate intercept is obtained with value $\delta L$ [49]. It is also assumed that the free volume of the films is approximately the same for all the coatings investigated and that no swelling by water occurs in the additive-free PDMS membrane. Moreover, the substrate film containing $4 \mathrm{wt} \%$ of the studied amphiphiles is assumed to be homogeneous with the amphiphile available on the surface, so no diffusion path is added from the lower film to the interface of the two films. Finally, due to the amphiphilic nature of the studied additives, formation of micelles is expected within the PDMS films. It has been reported elsewhere [54], that micelles lead to an important decrease of the kinetics of segregation of block copolymers in polymer hosts. It is assumed here that the diffusion is driven by unimers (amphiphile molecules which are not part of a micelle) and that the presence of micelles has a 
negligible effect on the diffusion process of the unimers. Under these assumptions, Equation 3 is used in this work to obtain diffusion coefficients for the studied amphiphiles. "It has not been part of the present investigation to verify the abovementioned assumptions".

\section{$\underline{2.5 \text { Contact angle measurements }}$}

The sessile drop method was used to monitor the contact angle of a droplet of water on the different PDMS films using Dataphysics OCA20 equipment. A droplet of $25 \mu \mathrm{l}$ of millipore water was placed on top of the different surfaces in a closed glass chamber, where the temperature was kept at $22^{\circ} \mathrm{C}$. The contact angle was analysed every 2 seconds, so that a contact angle-time profile could be obtained. Nevertheless, in Figures 4 and 5, only one point every 30/60 seconds is plotted for clarity. Regarding the volume of the water droplet, $25 \mu$ l was chosen as a compromise: it was sufficiently large to reduce evaporation effects, but small enough, with Eötvös number below 1, so that the weight of the droplet did not have a significant influence on the contact angle [55]. The volume of the water droplet was followed using the equipment's software, but the droplet was not refilled at any point to the original volume. Although volume loss by evaporation could not be completely avoided, detection of the time lags was not hindered.

\subsection{Seawater exposure}

The coatings applied on PMMA substrates (see last column in Table 1) were immersed in static conditions in seawater in Singapore ( $\left.1^{\circ} 23^{\prime} 33^{\prime \prime} \mathrm{N}, 103^{\circ} 58^{\prime} 34^{\prime \prime} \mathrm{E}\right)$ and in Barcelona ( $41^{\circ} 12^{\prime} 43^{\prime \prime} \mathrm{N}, 1^{\circ}$ 44 ' 0" E). The two locations were chosen due to their difference in water temperature and biofouling pressure. Visual inspection of biofouling on the panels was undertaken after 2 months of exposure.

\section{Results and discussion}

The main aim of this work was to study the diffusion properties of different PEG-based amphiphiles for fouling-release coatings (listed in Table 1). The addition of these surface-active additives to PDMS films has an influence on their surface properties. Fig. 4 shows how the contact angle of a water droplet changes within the first 10 minutes of contact with a PDMS film modified with some of the investigated amphiphiles. Note that a film with PEG $\left(\mathrm{M}_{\mathrm{w}}=400 \mathrm{~g} / \mathrm{mol}\right)$ and a film without additives have been added as references (coatings 13 and 14 in Table 1 and Figure 10). 


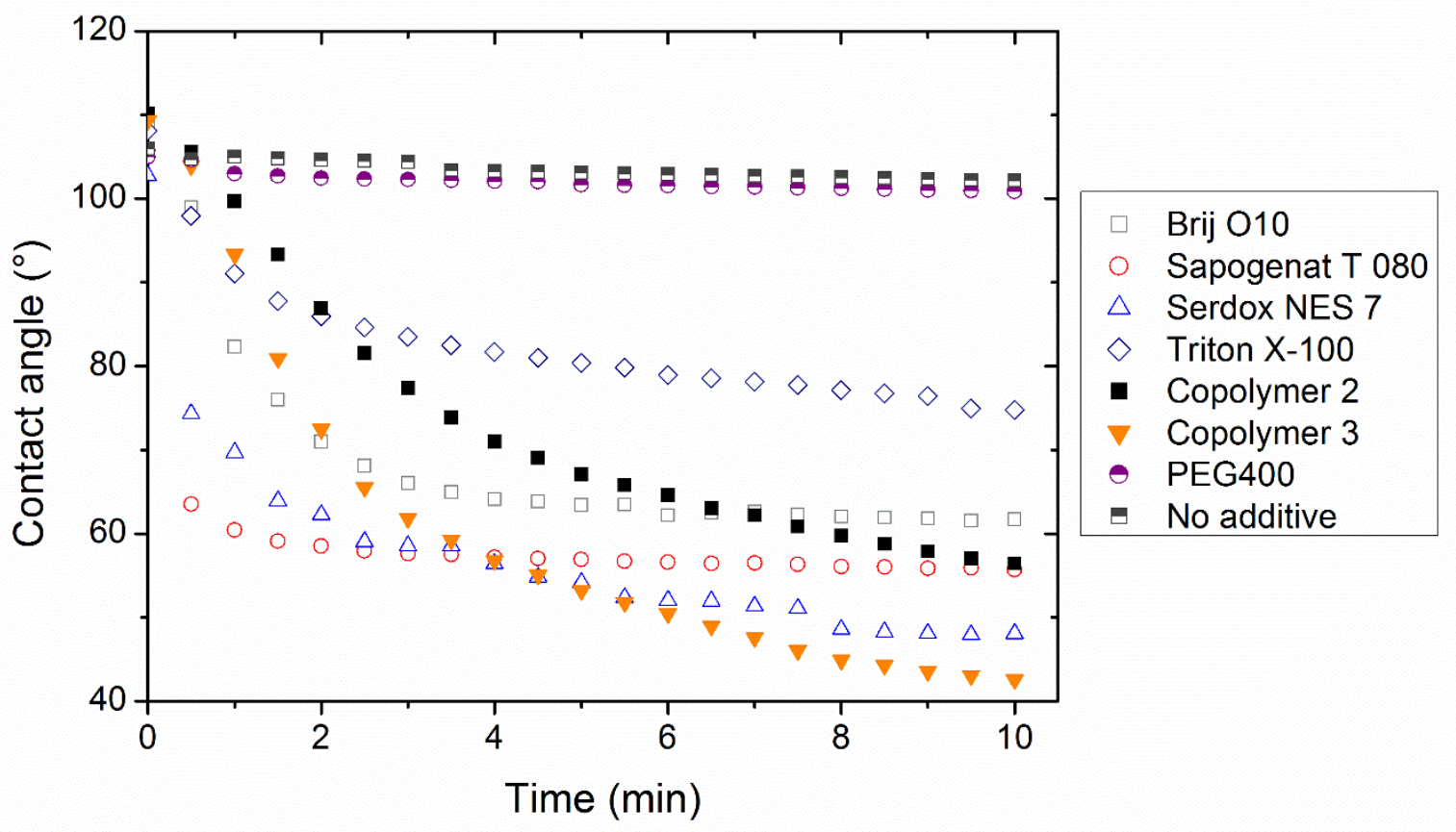

Figure 4. Contact angle evolution over time of a droplet of water on top of PDMS films containing some of the PEG-based additives investigated. A crosslinked PDMS film without additives and one using PEG as additive have been used as references.

In spite of some differences regarding the speed of change and the final value of the contact angle, it is clear that the addition of these amphiphilic compounds results in a change of hydrophilicity on the PDMS films' surfaces, both for alkyl-PEG, alkyl-aryl-PEG and PDMS-PEG amphiphiles. These surface-active additives can readily diffuse to the surface of the PDMS coatings and change the surface properties. These films have been used for the diffusion experiments (explained in a previous section) which are presented below. The PDMS film containing hydrophilic PEG does not experience a decrease in contact angle, probably due to the fact that the molecule is not surface-active and, therefore, the driving force for segregation is much weaker. 


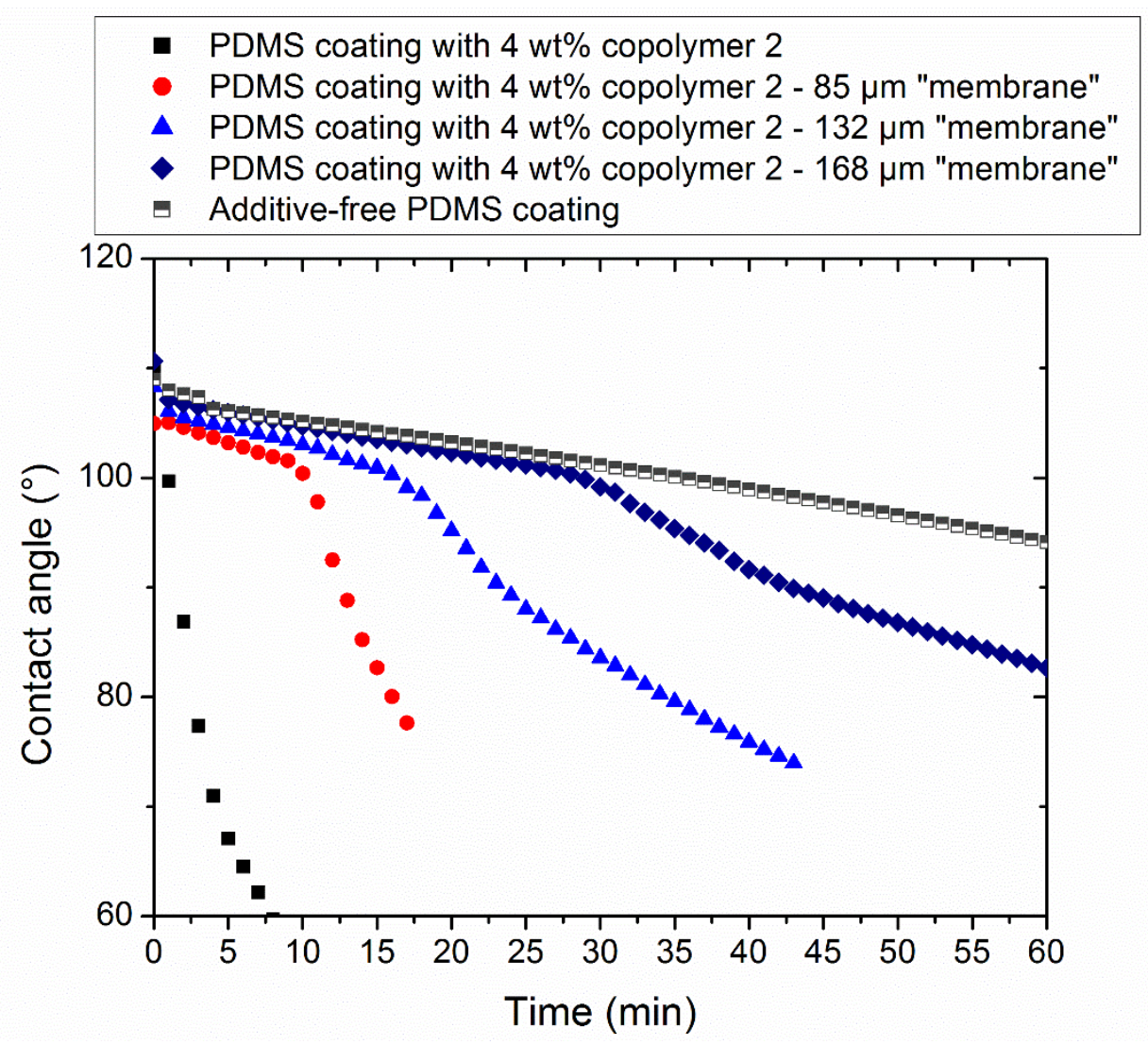

Figure 5. Contact angle of a droplet of water on top of PDMS films under different conditions. A PDMS film containing copolymer 2 as additive has been used, without (black squares) and with membranes of three different thicknesses, $85 \mu \mathrm{m}$ (red circles), $132 \mu \mathrm{m}$ (light blue triangles) and $168 \mu \mathrm{m}$ (dark blue diamonds). A PDMS film without additives is added for comparison (grey, half-filled squares).

Additive-free, PDMS films of different thicknesses have been cured separately and, after curing, placed between the additive-containing coating and the water droplet, as shown in Figure 3 . The contact angle has been monitored by a tensiometer. An example can be seen in Figure 5. Due to the hydrophobic nature of the PDMS, the contact angle is initially high $\left(\sim 106^{\circ}\right)$ and remains hydrophobic for some time, when the PDMS film is free of the additives used. When the added amphiphiles reach the surface, the contact angle suddenly drops. Not surprisingly, the contact angle drop time (i.e., the time lag) is dependent on thickness of the free film, as expected from Equation 2. For each thickness analysed (i.e. $85 \mu \mathrm{m}, 132 \mu \mathrm{m}$ and $168 \mu \mathrm{m}$ ), the time lags $L_{1}, L_{2}$ and $L_{3}$ have been obtained. The additive-free PDMS film used as reference remains hydrophobic throughout the experiment, though a decrease in contact angle of about $10^{\circ}$ is observed, probably due to evaporation effects. However, it is clear from Figure 5 
that the time lags can be accurately measured for the different thicknesses investigated, in spite of this uncertainty.

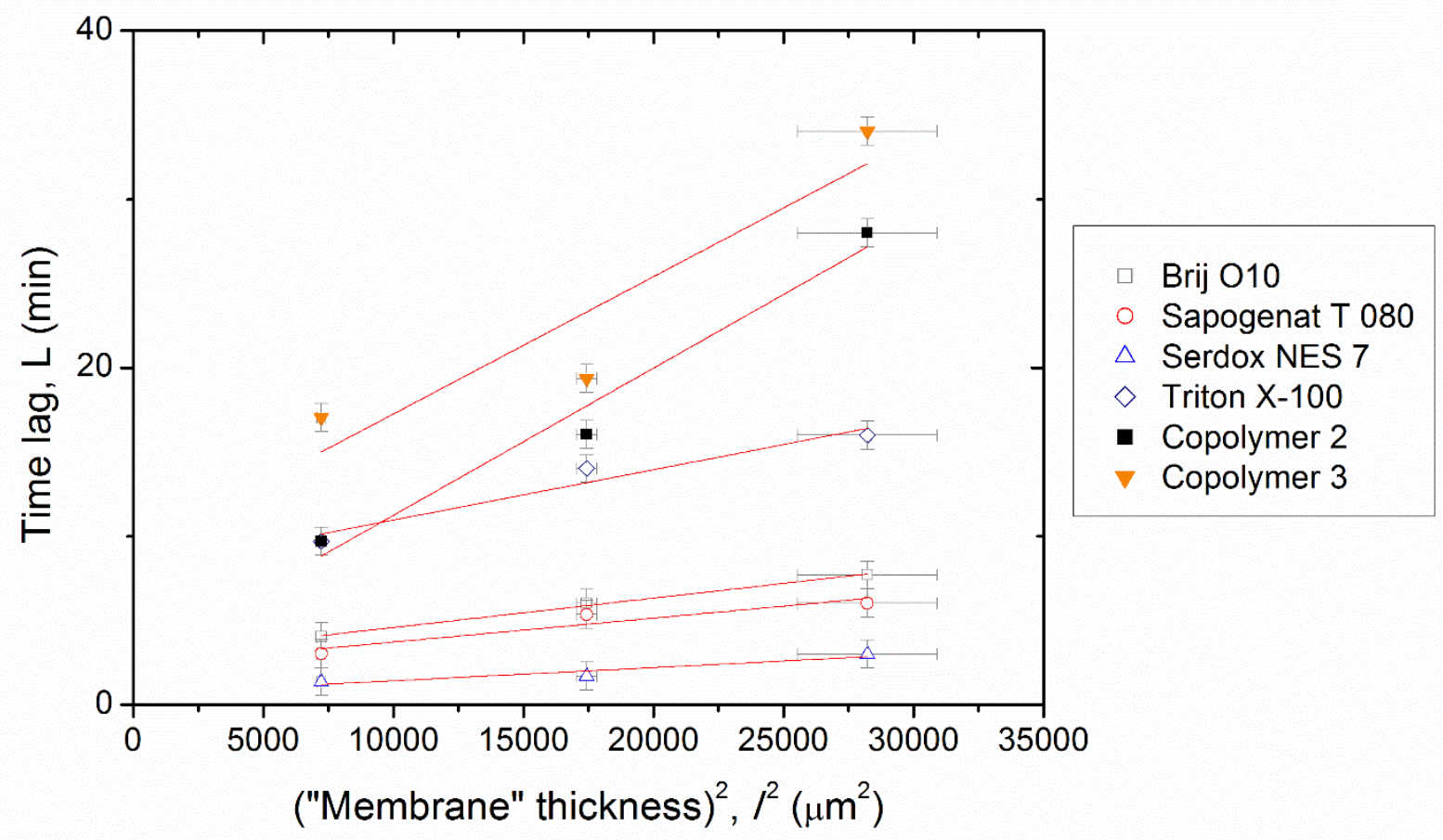

Figure 6. Experimental time lag (L) values against membrane squared thickness $(R)$ for some of the amphiphiles used, with the linear fit for each set of three points also shown. The slope of the curves has been used to calculate the diffusion coefficients (see Table 1). The y-axis error bars show the standard deviation of three repetitions of a single experiment, assuming its validity for all the experiments.

Fig 6 shows the results of plotting $L$ vs $R$ for some of the amphiphiles studied. The three experimental values obtained for each copolymer are fitted with a straight line and the slope is used to calculate the diffusion coefficients according to Equation 3. The results can be found in Table 1. Note that all the fitting curves present $R^{2}$ values between 0.862 and 0.999 . The error is mainly attributed to the variability of the thickness of the film of $168 \mu \mathrm{m}$ (see $\mathrm{x}$-axis error bar in Figure 6). It should also be taken into account that the high-thickness films might present higher inhomogeneity, due to the difference in curing time between the surface and the core of the film. This can also increase the variability of the results. Nonetheless, a clear tendency can be seen in Figure 6. The amphiphiles whose fitting curves present 
higher slopes (i.e. lower diffusion coefficients) present also the higher diffusion times (i.e. time lags) in the PDMS film.

\subsection{Effect of the molecular weight of the diffusant}

The values of the diffusion coefficients obtained range from $3.2 \times 10^{-12}$ to $3.5 \times 10^{-11} \mathrm{~m}^{2} / \mathrm{s}$. These values are compared to experimental diffusion coefficients obtained for different diffusing species through crosslinked PDMS networks. The diffusing species found in literature have been divided into two groups: (1) small molecules, with molecular weight below $1000 \mathrm{~g} / \mathrm{mol}$ and (2) PDMS chains, which include both linear and cyclic oligomers and polymers of PDMS of different sizes, all of them above $1000 \mathrm{~g} / \mathrm{mol}$. Note that no gases have been included. An overview of the different diffusants, experimental conditions and D values reported in the literature can be found in Table 2. 
Table 2. Experimental diffusion coefficients of different species in PDMS networks. The diffusants have been grouped in "small molecules" and "PDMS chains".

\begin{tabular}{|c|c|c|c|c|c|c|}
\hline & Diffusant & $\begin{array}{l}M_{w, \text { diffusant }} \\
(\mathrm{g} / \mathrm{mol})\end{array}$ & $\begin{array}{l}M_{c, \text { network }} \\
(\mathrm{g} / \mathrm{mol})\end{array}$ & $\begin{array}{l}\text { Temperature } \\
\left({ }^{\circ} \mathrm{C}\right)\end{array}$ & $\begin{array}{l}D\left(\mathrm{~m}^{2} / \mathrm{s}\right) \\
\cdot 10^{12}\end{array}$ & Reference \\
\hline \multirow{16}{*}{ 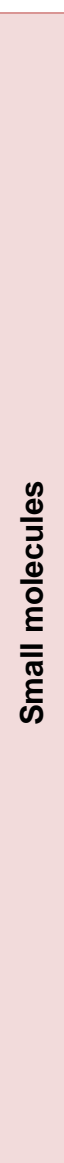 } & Hexadecanethiol & 260 & - & 22 & 59,0 & [56] \\
\hline & Hexadecanethiol & 260 & $35000^{a}$ & 22 & 39,0 & [56] \\
\hline & PBDE 28 & 410 & - & 20 & 25,1 & [57] \\
\hline & PBDE 47 & 490 & - & 20 & 24,5 & [57] \\
\hline & PBDE 99 & 570 & - & 20 & 19,5 & [57] \\
\hline & PBDE 100 & 570 & - & 20 & 50,1 & [57] \\
\hline & PBDE 153 & 640 & - & 20 & 17,0 & [57] \\
\hline & PBDE 154 & 640 & - & 20 & 16,6 & [57] \\
\hline & PBDE 959 & 960 & - & 20 & 15,8 & [57] \\
\hline & PCB4 & 220 & - & 20 & 29,5 & [58] \\
\hline & PCB52 & 290 & - & 20 & 21,9 & [58] \\
\hline & PCB149 & 360 & - & 20 & 19,5 & [58] \\
\hline & PCB204 & 430 & - & 20 & 16,6 & [58] \\
\hline & Anthracene & 180 & - & 20 & 37,2 & [58] \\
\hline & Fluorene & 170 & - & 20 & 52,5 & [58] \\
\hline & Pyrene & 200 & - & 20 & 24,0 & [58] \\
\hline \multirow{10}{*}{ 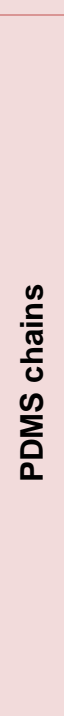 } & PDMS linear & 4700 & 36000 & 23 & 1,6 & [59] \\
\hline & PDMS linear & 11500 & 36000 & 23 & 1,0 & [59] \\
\hline & PDMS linear & 3500 & 7400 & 26 & 6,2 & [60] \\
\hline & PDMS linear & 3600 & 7400 & 26 & 5,1 & [60] \\
\hline & PDMS linear & 5300 & 7400 & 26 & 3,2 & [60] \\
\hline & PDMS linear & 6200 & 7400 & 26 & 3,0 & [60] \\
\hline & PDMS linear & 3100 & 3700 & 26 & 6,1 & {$[60]$} \\
\hline & PDMS linear & 3400 & 3700 & 26 & 5,4 & {$[60]$} \\
\hline & PDMS linear & 4600 & 3700 & 26 & 3,4 & [60] \\
\hline & PDMS linear & 5000 & 3700 & 26 & 3,4 & [60] \\
\hline
\end{tabular}




\begin{tabular}{llcccc}
\hline PDMS cyclic & 4300 & 1900 & 23 & 5,5 & {$[61]$} \\
\hline PDMS cyclic & 4300 & 7400 & 23 & 7,6 & {$[61]$} \\
\hline PDMS linear & 4700 & 1900 & 23 & 4,8 & {$[61]$} \\
\hline PDMS linear & 4700 & 7400 & 23 & 6,3 & {$[61]$}
\end{tabular}

a estimated from the reported viscosity using Equation 3

Although the temperature of these experiments and the molecular weight of the network $\left(\mathrm{Mc}_{\mathrm{c}}\right)$ differ to some extent, they exhibit comparable values. Regarding the impact of the molecular weight of the network, it has been previously shown [59] that it has a very small influence on $D\left(D=k_{c} \cdot M_{c}{ }^{0,2}\right)$. With regards to the temperature of the experiments, all the reported values are between $20^{\circ} \mathrm{C}$ and $26^{\circ} \mathrm{C}$, which is assumed not to have a strong effect on the results. 
a)

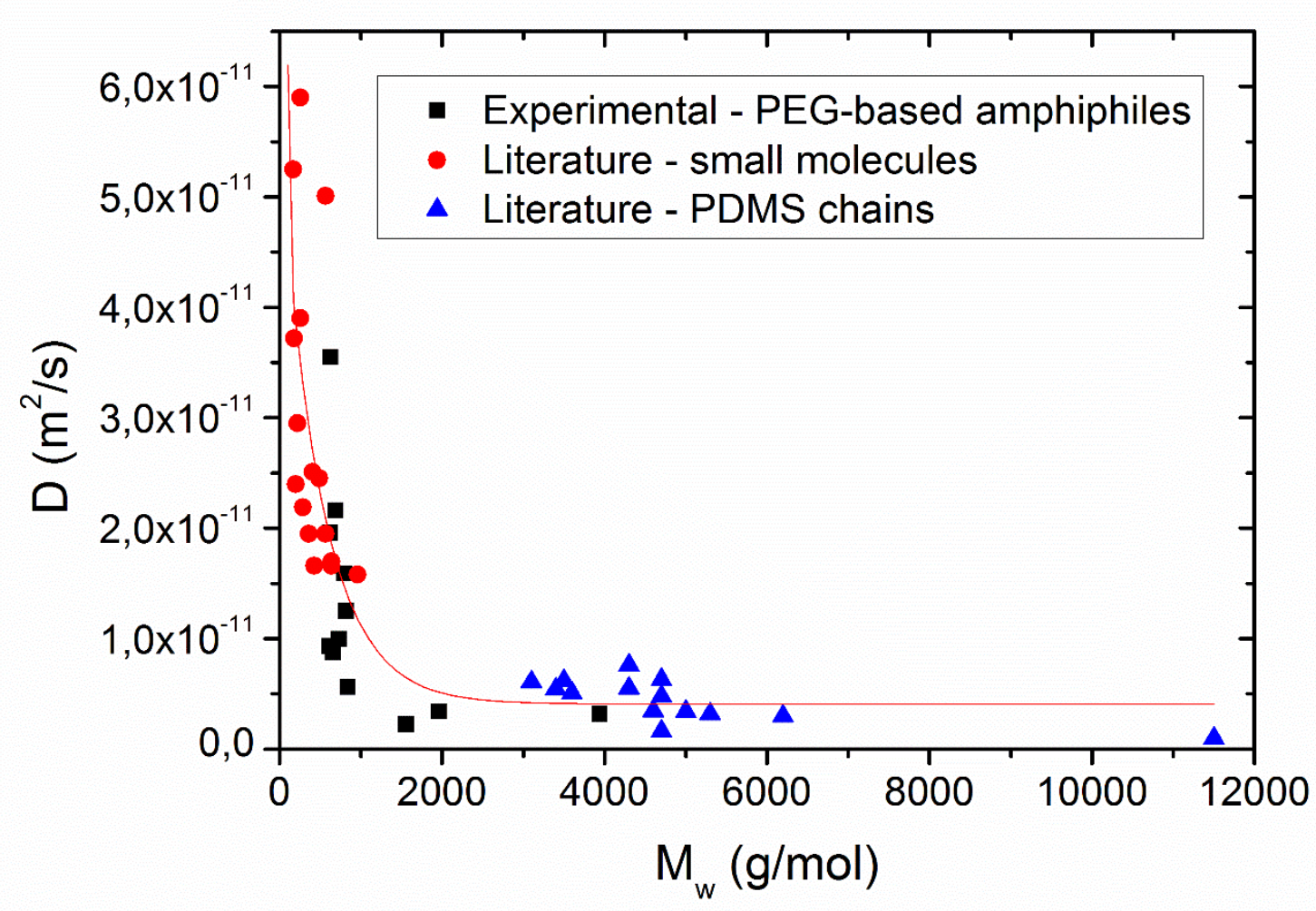

b)

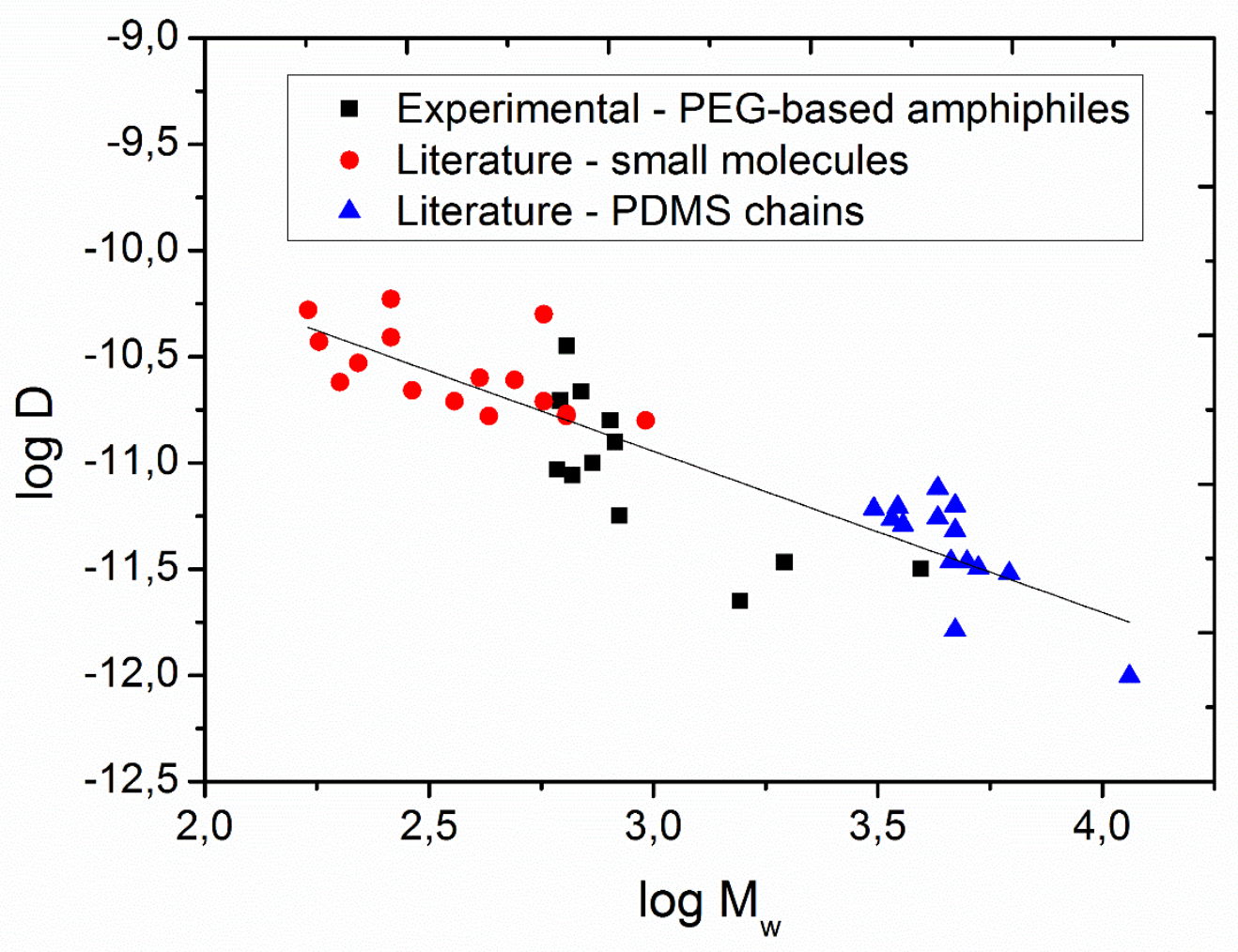


Figure 7. Diffusion coefficient of the studied additives and found in the literature plotted against their molecular weights (a). A log-log plot of the diffusion data is also shown (b). A logarithimic regression has been added for visual help in (a), while a liner regression has been added in (b).

In Figure 7, the diffusion coefficients versus their $M_{w}$ are shown for all the studied amphiphiles, together with values from the literature. It can be seen that the values obtained here are in agreement with what has been published so far, showing a power dependence of the diffusion coefficient with respect to the molecular weight of the diffusing species $\left(D=k_{w} \cdot M_{w}{ }^{\alpha}\right)$, as reported previously in the literature [52]. In this case, $\alpha$ has a value of $-0,8$ ( -1 if only the experimental results obtained here are taken into account). This result is in agreement with what has been reported for PDMS diffusing through PDMS networks $[59,60]$ with $\alpha$ between -1 and $-1,3$. These values of $\alpha$ are significantly lower than for other polymeric systems. For example, it has been shown that $\alpha=-1,7$ for linear polyisoprene chains into polyisoprene networks [62], in spite of both PDMS and polyisoprene networks being great above their $\mathrm{T}_{\mathrm{g}}$. Therefore, the molecular weight of the diffusant has a small effect on the diffusion coefficient in PDMS compared to other polymeric networks. This is reflected in the narrow range of diffusion coefficients obtained, all lying within the same order of magnitude.

Let us compare, as an example, the amphiphiles Triton X-100, Sapogenat T080, Brij O10 and Serdox NES, whose chemical structures are shown in Figure 8. In spite of having very similar molecular weights and number of PEG units, their diffusion coefficients differ up to a factor of about 4 . This fact might be an indication that other parameters than the molecular weight such as the chemistry and structure of the hydrophobic block of the amphiphiles should be taken into account. It has been previously shown for small molecules diffusing in different polymer hosts like polypropylene (PP) and PDMS, that the molecular weight cannot be used as a universal parameter when comparing the diffusion coefficients of species with different chemistries and structures. Instead, other variables have been used, for example, a molecular volume corrected by a shape factor [63] or the total surface area of the molecule [58], showing much better agreement with $D$ than the molecular weight. 


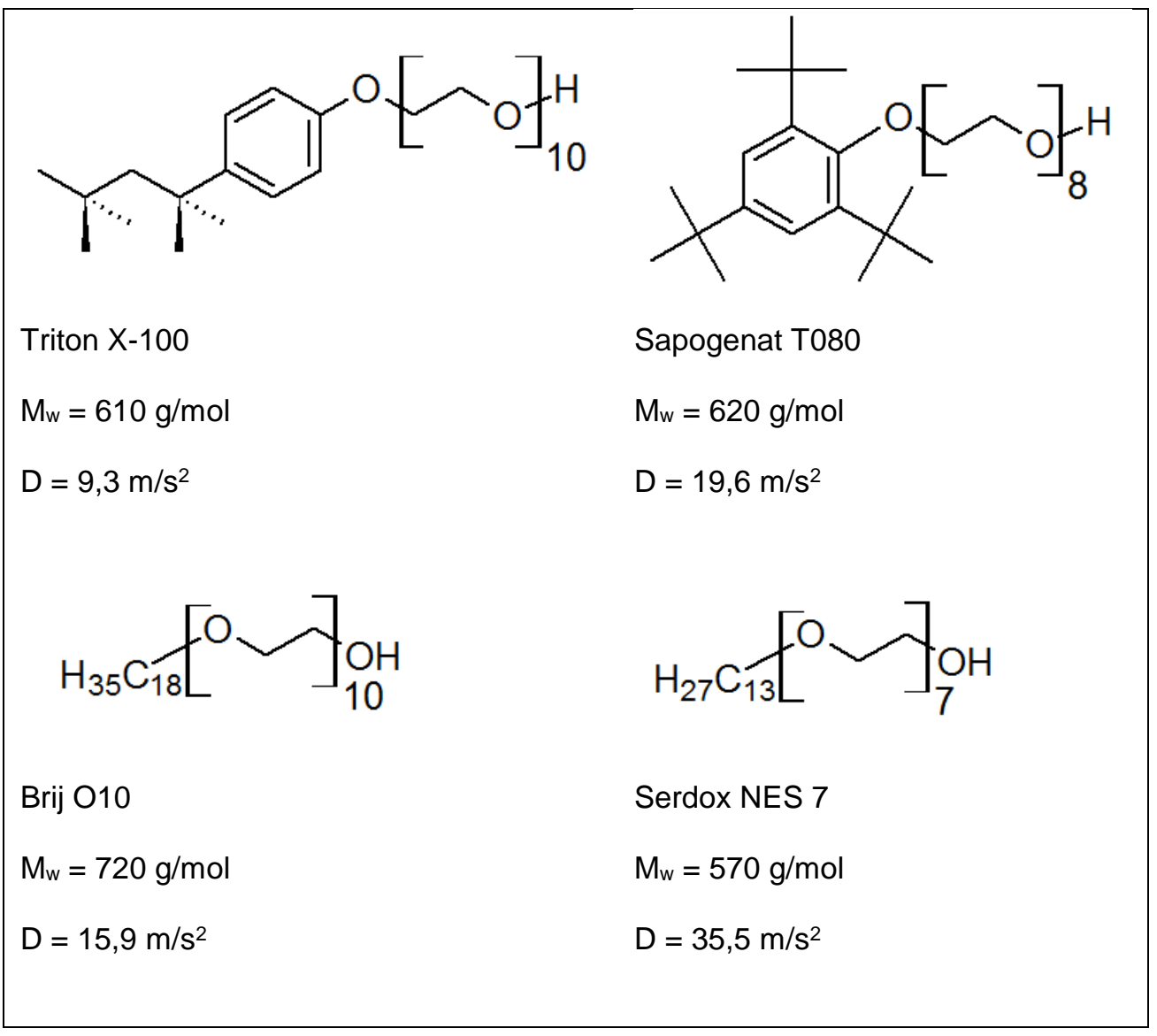

Figure 8. Chemical structure, diffusion coefficient (D) and molecular weight $\left(M_{w}\right)$ of the amphiphiles Triton X-100, Sapogenat T 080, Brij O10 and Serdox NES 7.

\subsection{Effect of the amphiphilicity (polarity) of the diffusant}

To assess the effect of the chemistry of the studied amphiphiles on the diffusion coefficient, the hydrophilic-lypophilic balance (HLB) value is used. The HLB value has been traditionally used to characterize the solubility of surfactants, which determines their behaviour in many applications.

HLB values can be experimentally obtained or theoretically estimated. The saponification value has been extensively used to determine HLB values for different surfactants. For non-ionic surfactants, however, Griffin [64] suggested Equation 4 as an easy alternative to obtain HLB values when the saponification value is not available.

$$
H L B=\frac{E+P}{5}
$$

(Equation 4) 
where $E$ is the weight percentage of oxyethylene content, and $P$ is the weight percent of polyhydric alcohol content (e.g. glycerol). It should be noted that Equation 4 only accounts for the weight fraction of the hydrophilic and hydrophobic groups, while the structure of the two blocks or the presence of aryl groups is neglected. Nonetheless, it is a broadly used formula in the industry of these kinds of amphiphiles.

Figure 9 shows the correlation between HLB value with the obtained diffusion coefficient for the different amphiphiles. It can be seen that no apparent relationship exists between the variables. To study the influence of the chemistry and the structure of these amphiphilic molecules, a more systematic approach should be used, with synthesis of well-defined amphiphiles, varying the length and the chemical structure of the two blocks. This is, however, outside the scope of this work.

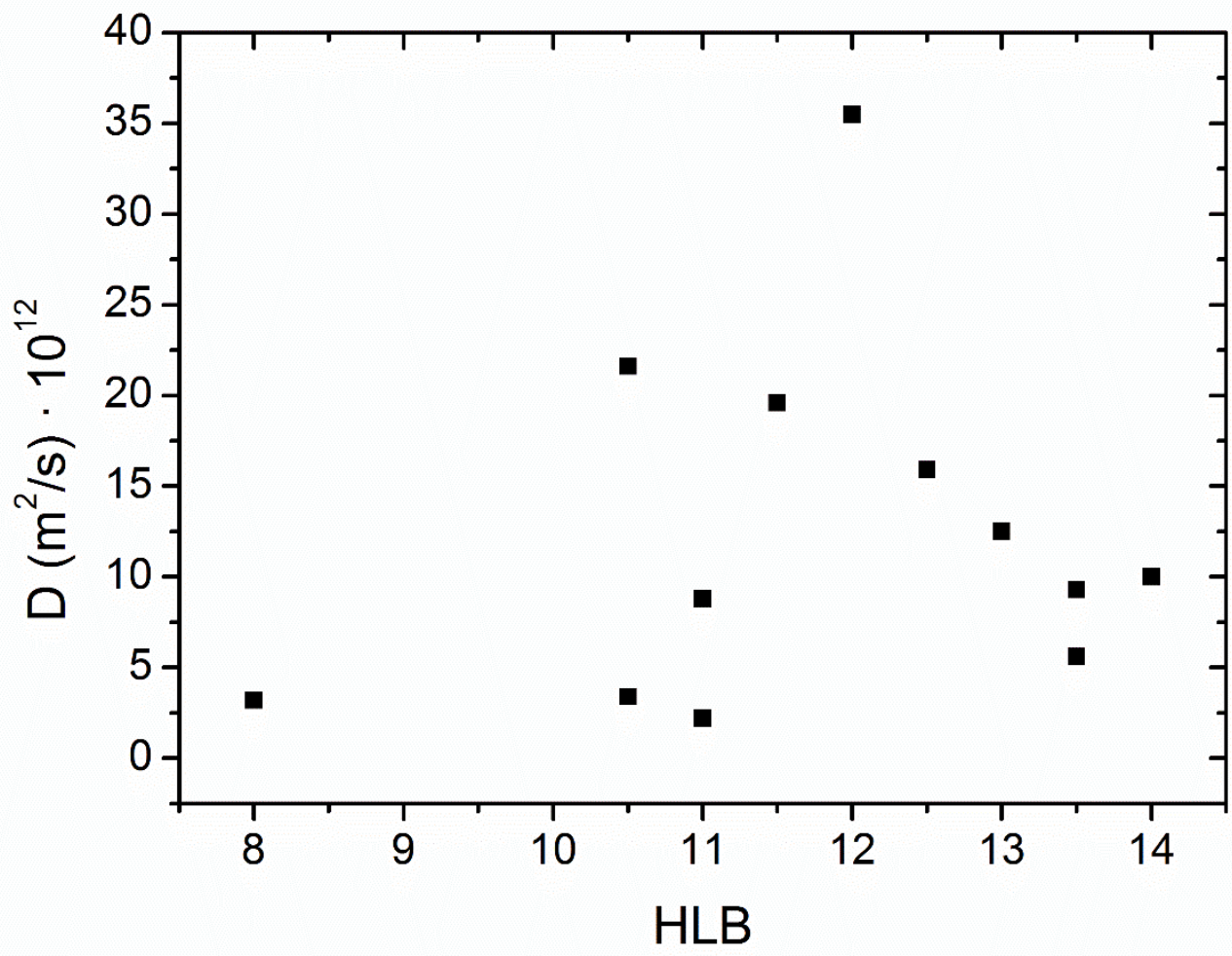

Figure 9. Diffusion coefficient of the studied amphiphiles against their hydrophilic-lyphophilic balance (HLB) value.

\subsection{Effect of the studied amphiphiles on the biofouling-resistance properties of PDMS coatings}


Finally, the fouling-resistance properties of these amphiphiles have been analysed. PDMS coatings containing 4 wt\% of the different additives investigated were sent to two different locations for seawater immersion, Barcelona and Singapore. Half of each coated panel was overcoated with an additive-free PDMS coating to examine the diffusion of these additives in real-life, seawater conditions. After 2 months of exposure, a visual inspection of the coatings was undertaken.

Figure 10 shows the coatings after 2 months exposure in (a) Barcelona and (b) Singapore. As shown, the biofouling community consisted mainly of slime, with some tubeworms and bryozoa being present in Singapore as well.

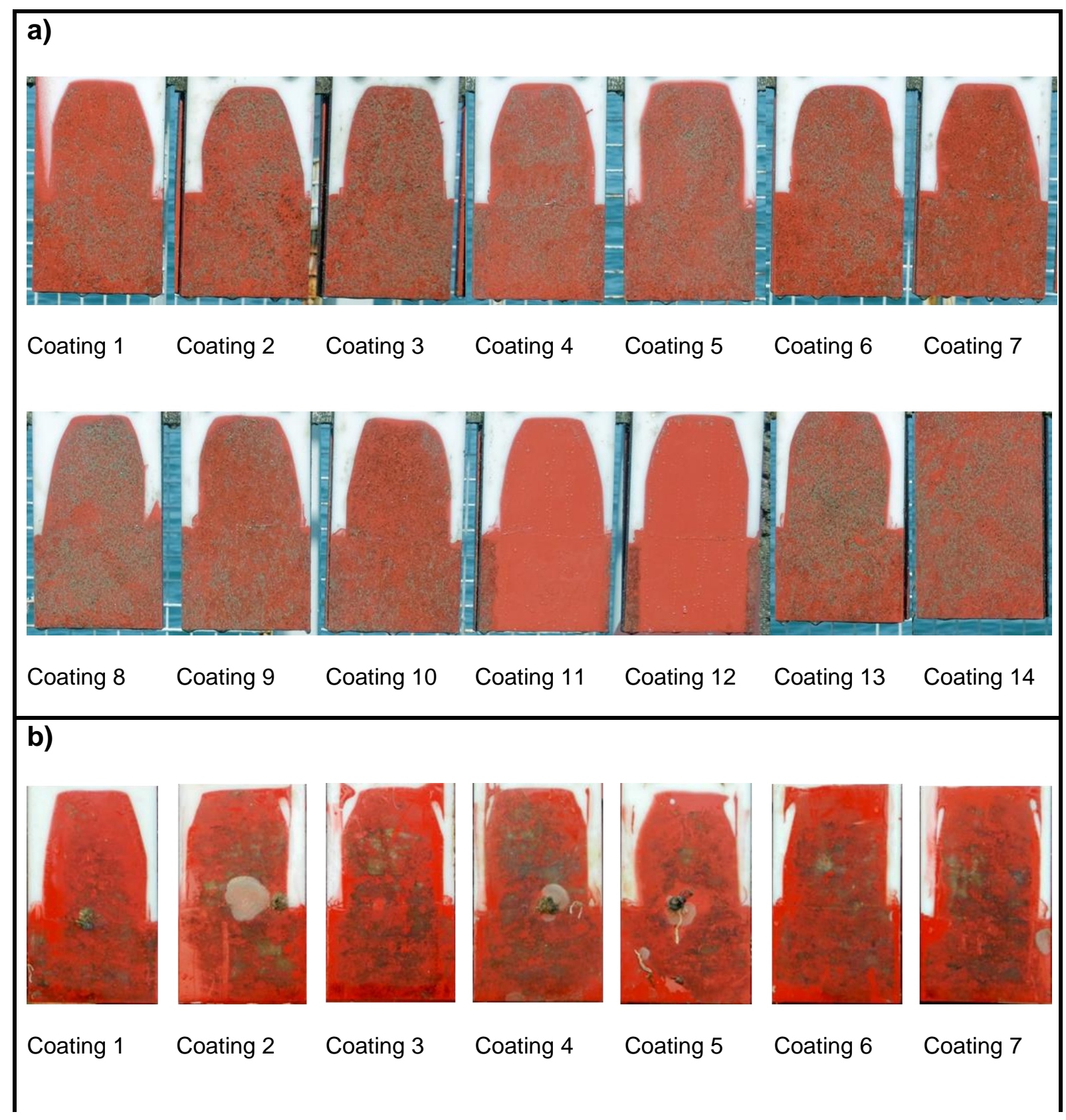




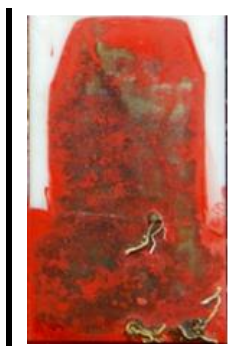

Coating 8
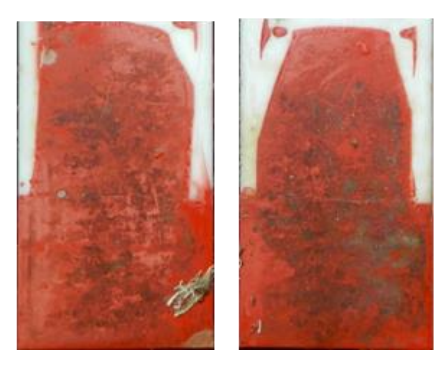

Coating 9

Coating 10

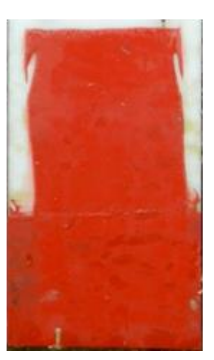

Coating 11
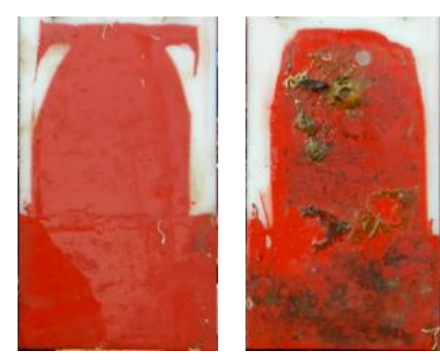

Coating 12 Coating 13

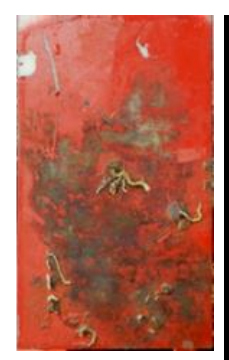

Coating 14

Figure 10. Coatings exposed to seawater in (a) Barcelona and (b) Singapore after 2 months of exposure (see Table 1).

The two reference coatings analysed, coatings 13 and 14 (the coating containing PEG400 and the additive-free coating) show significant amounts of biofouling after 2 months of exposure, confirming their poor properties regarding fouling-resistance in static conditions. By comparison with these two reference coatings, the biofouling-resistance of the modified coatings with PEG-based amphiphiles is discussed below.

First of all, all the alkyl-PEG and alkyl-aryl-PEG amphiphiles investigated show poor fouling-resistance properties in the conditions studied, as the amount of biofouling on their surfaces reached the same extent as on the reference coatings (coatings 1-5 for alkyl-PEG and 6-9 for alkyl-aryl-PEG amphiphiles). This behaviour cannot be explained by a low diffusivity of these species, as it has been shown that they can diffuse through PDMS films in relatively short amounts of time, with lower diffusion coefficients than PDMS-PEG copolymers.

On the other hand, some of the PDMS-PEG amphiphiles investigated show good fouling-resistance properties, both in the overcoated and the non-overcoated area (see coatings 11 and 12). This fact proves that it is possible to functionalize PDMS surfaces by adding small amounts of amphiphiles in the uncured PDMS mixture. Moreover, these copolymers can diffuse, as previously shown with the time lag method, through PDMS films and, therefore, provide fouling-resistance properties to PDMS coatings that were, originally, additive-free. However, the PDMS-PEG amphiphile with the shortest PDMS chain shows no fouling-resistance properties.

Amphiphiles with similar diffusion coefficients but different hydrophobic block (for example, Sapogenat T130 or Triton X-100) present significantly worse biofouling-resistance properties when compared to copolymers 2 and 3. Similarly, copolymer 1, the PDMS-PEG amphiphile with lower molecular weight, 
also presents significant amounts of biofouling. This fact, together with the presence of fouling on the coatings containing alkyl-PEG and alkyl-aryl-PEG amphiphiles, shows the importance of the anchoring block of these amphiphilic molecules. However, it cannot be clarified whether it is the chemistry or the molecular weight of the anchoring group, which plays the major role in this process, because all the alkyl-PEG and alkyl-aryl-PEG amphiphiles investigated had low molecular weight hydrophobic blocks. Some previous studies have investigated the stability of different PEG-based surfactants and copolymers employed as additives in PDMS films, by soaking the films in water for different exposure times. It was reported that surfactants containing an alkyl group as hydrophobic block show poor stability, and the hydrophilicity of the PDMS films diminish upon immersion [30,65]. Conversely, copolymers using PDMS as anchoring block exhibit superior stability when compared to their alkylbased homologues. However, only short exposure times (20 hours) were evaluated [30].

The importance of the anchoring group could be two fold. On one hand, it can influence the surface coverage properties of the surfactant, which is crucial with regards to the protection against biofouling. On the other hand, the anchoring group controls the solubility, stability and release of the amphiphiles to seawater, dictating to a big extent the long-term stability of these additives. It has been shown, nonetheless, that it is possible to obtain fouling-resistance properties by tuning the size and structure of the hydrophobic block of the added amphiphiles without compromising their diffusion capabilities. It should be noted that, in systems with another network (with a higher a value), changing the molecular weight of the blocks of the amphiphiles will result in a $M_{w}$ increase that can have large consequences on the diffusion coefficient of the amphiphiles, and thus might compromise the final fouling-resistance properties provided.

\section{Conclusions}

The diffusion of different PEG-based surface-active amphiphiles has been studied in this project. A novel method has been developed for the study of the diffusion of amphiphiles in polymeric networks, such as PDMS. It is based on a time lag method modified with a tensiometer, that tracks the contact angle of a water droplet on a PDMS surface. Compared to other methods used for diffusion experiments, it provides results in a much faster way without sample preparation. The method has been successfully used to study the diffusion of additives for fouling-release coatings and experimental diffusion coefficients have been estimated for PEG-based amphiphiles in crosslinked PDMS films. 
The diffusion coefficient values obtained have been compared to what has been published up to date. The diffusion coefficients determined for the studied amphiphiles are in agreement with those of small diffusing molecules and polymeric PDMS chains in PDMS films. The molecular weight of the diffusant has an influence on D following a power law, although the effect of the molecular weight is significantly lower than for diffusing molecules in other polymeric networks. In addition to the importance of the molecular weight of the molecule, some differences between compounds of similar molecular weight suggest that parameters like the structure and chemistry of the molecules also play a role in the diffusion process. Finally, coatings immersed in seawater have shown that copolymers with PDMS as anchoring group lead to the lowest amount of biofouling, both in the overcoated and the pristine areas. These are very interesting results from two perspectives. On one side, they confirm that PDMS surfaces can be easily functionalized by the addition of small amounts of surface-active additives in an easy and cheap way. Moreover, this process is not limited by the diffusion coefficient of these additives, in spite of the relatively high molecular weight of some of the amphiphiles used. Finally, the importance of the anchoring block of the amphiphilic molecules on their fouling-resistance properties has been shown. Amphiphiles with PEG blocks of the same length show very different fouling-resistance properties when the hydrophobic block is changed, with amphiphiles using PDMS as hydrophobic block showing the best performance. These large differences regarding fouling-resistance properties exist for amphiphiles that have coefficient diffusion values in the same range, confirming that the process is not diffusion-limited. Instead, the structure and chemistry of the hydrophobic block exhibit a very strong influence on the fouling-resistance properties of these molecules.

\section{Acknowledgements}

The financial support of the Danish Ministry for Science and Technology is gratefully acknowledged.

\section{References}

[1] B. Björkner, A. Pontén, E. Zimerson, M. Frick, Plastic materials, in: P.J. Frosch, T. Menné, J.P. Lepoittevin (Eds.), Contact Dermatitis, 4th ed., Springer, Heidelberg, Germany, 2006: pp. 583622.

[2] A.P. Narrainen, L.R. Hutchings, I. Ansari, R.L. Thompson, N. Clarke, Multi-End-Functionalized 
Polymers: Additives to Modify Polymer Properties at Surfaces and Interfaces, Macromolecules. 40 (2007) 1969-1980. doi:10.1021/ma062349y.

[3] H. Lee, L.A. Archer, Functionalizing polymer surfaces by surface migration of copolymer additives: role of additive molecular weight, Polymer. 43 (2002) 2721-2728. doi:10.1016/S0032-3861(02)00041-1.

[4] C.D. James, C. Jeynes, N.P. Barradas, L. Clifton, R.M. Dalgliesh, R.F. Smith, S.W. Sankey, L.R. Hutchings, R.L. Thompson, Modifying polyester surfaces with incompatible polymer additives, React. Funct. Polym. 89 (2015) 40-48. doi:10.1016/j.reactfunctpolym.2015.03.002.

[5] T. Miyata, Y. Nakanishi, T. Uragami, Ethanol Permselectivity of Poly(dimethylsiloxane) Membranes Controlled by Simple Surface Modifications Using Polymer Additives, Macromolecules. 30 (1997) 5563-5565. doi:10.1021/ma9618843.

[6] Z. Wu, K. Hjort, Surface modification of PDMS by gradient-induced migration of embedded Pluronic, Lab Chip. 9 (2009) 1500. doi:10.1039/b901651a.

[7] T. Røn, I. Javakhishvili, S. Hvilsted, K. Jankova, S. Lee, Ultralow Friction with Hydrophilic Polymer Brushes in Water as Segregated from Silicone Matrix, Adv. Mater. Interfaces. 3 (2016) 1500472. doi:10.1002/admi.201500472.

[8] T.D. Prichard, B.D. Vogt, Comparison of flocculated and dispersed single-wall carbon nanotube-based coatings using nonionic surfactants, Polym. Eng. Sci. 53 (2013) 69-77. doi:10.1002/pen.23237.

[9] J. Texter, P. Ziemer, S. Rhoades, D. Clemans, Bactericidal silver ion delivery into hydrophobic coatings with surfactants, J. Ind. Microbiol. Biotechnol. 34 (2007) 571-575. doi:10.1007/s10295-007-0228-2.

[10] M.S. El-Aasser, J. Tang, X. Wang, E.S. Daniels, V.L. Dimonie, E.D. Sudol, Advances in emulsion polymerization for coatings applications: Latex blends and reactive surfactants, J. Coatings Technol. 73 (2001) 51-63. doi:10.1007/BF02698376.

[11] S.J. Hinder, C. Lowe, J.T. Maxted, J.F. Watts, Migration and segregation phenomena of a silicone additive in a multilayer organic coating, Prog. Org. Coatings. 54 (2005) 104-112. 
doi:10.1016/j.porgcoat.2005.04.007.

[12] M. Horgnies, E. Darque-Ceretti, Study of siloxane additives migration to the surface of polyester-(melamine)-polyurethane coatings: Aging effects after ethanol cleaning, Prog. Org. Coatings. 55 (2006) 27-34. doi:10.1016/j.porgcoat.2005.09.006.

[13] D. Juhué, Y. Wang, J. Lang, O.-M. Leung, M.C. Goh, M.A. Winnik, Surfactant exudation in the presence of a coalescing aid in latex films studied by atomic force microscopy, J. Polym. Sci. Part B Polym. Phys. 33 (1995) 1123-1133. doi:10.1002/polb.1995.090330716.

[14] X. Trier, K. Granby, J.H. Christensen, Polyfluorinated surfactants (PFS) in paper and board coatings for food packaging, Environ. Sci. Pollut. Res. 18 (2011) 1108-1120. doi:10.1007/s11356-010-0439-3.

[15] B. Rixens, R. Severac, B. Boutevin, P. Lacroix-Desmazes, Y. Hervaud, Migration of Additives in Polymer Coatings: Phosphonated Additives and Poly(vinylidene chloride)-Based Matrix, Macromol. Chem. Phys. 206 (2005) 1389-1398. doi:10.1002/macp.200500030.

[16] C.J. Kavanagh, G.W. Swain, B.S. Kovach, J. Stein, C. Darkangelo-Wood, K. Truby, E. Holm, J. Montemarano, A. Meyer, D. Wiebe, The Effects of Silicone Fluid Additives and Silicone Elastomer Matrices on Barnacle Adhesion Strength, Biofouling. 19 (2003) 381-390. doi:10.1080/08927010310001623296.

[17] A. Camós Noguer, S.M. Olsen, S. Hvilsted, S. Kiil, Long-term stability of PEG-based antifouling surfaces in seawater, J. Coatings Technol. Res. 13 (2016) 567-575. doi:10.1007/s11998-0169801-9.

[18] P.C.W. Thorlaksen, A. Blom, U. Bork, Novel fouling control coating compositions, WO2011076856, 2011.

[19] P.C.W. Thorlaksen, Fouling control coating compositions comprising polysiloxane and pendant hydrophilic oligomer/polymer moieties, WO2013000478, 2013.

[20] D.C. Webster, R.B. Bodkhe, Functionalized silicones with polyalkylene oxide side chains, WO2013052181, 2013. 
[21] K.J. Reynolds, B. V. Tyson, Anti-fouling compositions with a fluorinated oxyalkylene-containing polymer or oligomer, WO 2014131695, 2014.

[22] J. Stein, T.B. Brydon, J.A. Cella, Condensation curable silicone foul release coatings and articles coated therewith, US006107381, 2000.

[23] W.P. Liao, Antifouling system comprising silicone hydrogel, WO 2014126643, 2014.

[24] S. Tanino, Antifouling coating composition, antifouling coating film, antifouling substrate, and method for improving storage stability of antifouling coating composition, EP2921538, 2015.

[25] J. Dewitte, G. Piessens, R. Dams, Fluorochemical intermediates, surfactants and their use in coatings, JOCCA - Surf. Coatings Int. 78 (1995) 58-64.

[26] E. Berndt, S. Behnke, A. Dannehl, A. Gajda, J. Wingender, M. Ulbricht, Functional coatings for anti-biofouling applications by surface segregation of block copolymer additives, Polymer. 51 (2010) 5910-5920. doi:10.1016/j.polymer.2010.10.002.

[27] R.B. Bodkhe, S.J. Stafslien, N. Cilz, J. Daniels, S.E.M. Thompson, M.E. Callow, J.A. Callow, D.C. Webster, Polyurethanes with amphiphilic surfaces made using telechelic functional PDMS having orthogonal acid functional groups, Prog. Org. Coatings. 75 (2012) 38-48. doi:10.1016/j.porgcoat.2012.03.006.

[28] H.S. Sundaram, Y. Cho, M.D. Dimitriou, C.J. Weinman, J.A. Finlay, G. Cone, M.E. Callow, J.A. Callow, E.J. Kramer, C.K. Ober, Fluorine-free mixed amphiphilic polymers based on PDMS and PEG side chains for fouling release applications, Biofouling. 27 (2011) 589-602. doi:10.1080/08927014.2011.587662.

[29] J. Lee, H. Lee, J. Andrade, Blood compatibility of polyethylene oxide surfaces, Prog. Polym. Sci. 20 (1995) 1043-1079. doi:10.1016/0079-6700(95)00011-4.

[30] A. Fatona, Y. Chen, M. Reid, M.A. Brook, J.M. Moran-Mirabal, One-step in-mould modification of PDMS surfaces and its application in the fabrication of self-driven microfluidic channels, Lab Chip. 15 (2015) 4322-4330. doi:10.1039/C5LC00741K.

[31] M. Inutsuka, N.L. Yamada, K. Ito, H. Yokoyama, High density polymer brush spontaneously 
formed by the segregation of amphiphilic diblock copolymers to the polymer/water interface, ACS Macro Lett. 2 (2013) 265-268. doi:10.1021/mz300669q.

[32] H. Lee, L.A. Archer, Functionalizing Polymer Surfaces by Field-Induced Migration of Copolymer Additives. 1. Role of Surface Energy Gradients, Macromolecules. 34 (2001) 45724579. doi:10.1021/ma001278e.

[33] N.J. Lin, H.S. Yang, Y. Chang, K.L. Tung, W.H. Chen, H.W. Cheng, S.W. Hsiao, P. Aimar, K. Yamamoto, J.Y. Lai, Surface self-assembled pegylation of fluoro-based pvdf membranes via hydrophobic-driven copolymer anchoring for ultra-stable biofouling resistance, Langmuir. 29 (2013) 10183-10193. doi:10.1021/la401336y.

[34] T. Røn, J.B. Madsen, N. Nikorgeorgos, S. Lee, Role of Charges of the Surface-grafted Polymer Chains for Aqueous Lubrication at a Nonpolar Interface, J. Korean Soc. Tribol. Lubr. Eng. 30 (2014) 247-255. doi:10.9725/kstle.2014.30.5.247.

[35] F.W. Wang, B.F. Howell, A novel fluorescence technique for measurements of additive migration from polymers, Polymer. 25 (1984) 1626-1628. doi:10.1016/0032-3861(84)90157-5.

[36] V. V. Krongauz, W.F. Mooney, J.W. Palmer, J.J. Patricia, Real-time monitoring of diffusion in polymer films using fluorescent tracer, J. Appl. Polym. Sci. 56 (1995) 1077-1083. doi:10.1002/app.1995.070560907.

[37] C.M. Mahoney, J. Yu, J.A. Gardella, Depth Profiling of Poly(L-lactic acid)/Triblock Copolymer Blends with Time-of-Flight Secondary Ion Mass Spectrometry, Anal. Chem. 77 (2005) 35703578. doi:10.1021/ac048274i.

[38] J. Wen, G. Somorjai, F. Lim, R. Ward, XPS Study of Surface Composition of a Segmented Polyurethane Block Copolymer Modified by PDMS End Groups and Its Blends with Phenoxy, Macromolecules. 30 (1997) 7206-7213. doi:10.1021/ma961442r.

[39] B. Martinez-Lopez, P. Chalier, V. Guillard, N. Gontard, S. Peyron, Determination of mass transport properties in food/packaging systems by local measurement with Raman microspectroscopy, J. Appl. Polym. Sci. 131 (2014) 40958. doi:10.1002/app.40958.

[40] V. Dobbyn, R. Howley, P. Kirwan, P. McLoughlin, Measurement of the Rates of Diffusion of 
Halomethanes into Polymer Films Using ATR-FTIR Spectroscopy, Int. J. Environ. Anal. Chem. 83 (2003) 643-652. doi:10.1080/0306731021000019214.

[41] M.D. Stewards, S. V. Postnikov, H. Vi Tran, D.R. Medeiros, M.A. Nierode, T. Cao, J. Byers, S.E. Webber, C. Grant Willson, Measurement of acid diffusivity in thin polymer films above and below Tg, ACS Polym. Mater. Sci. Eng. 81 (1999).

[42] A.J.M. Valente, A.Y. Polishchuk, V.M.M. Lobo, H.D. Burrows, Transport Properties of Concentrated Aqueous Sodium Dodecyl Sulfate Solutions in Polymer Membranes Derived from Cellulose Esters, Langmuir. 16 (2000) 6475-6479. doi:10.1021/la000286l.

[43] J.A. Faucher, E.D. Goddard, Diffusion and sorption phenomena in neonatal rat stratum corneum, J. Colloid Interface Sci. 65 (1978) 444-450. doi:10.1016/0021-9797(78)90095-4.

[44] A.J. Barry, Viscometric Investigation of Dimethylsiloxane Polymers, J. Appl. Phys. 17 (1946) 1020. doi:10.1063/1.1707670.

[45] H.A. Daynes, The Process of Diffusion through a Rubber Membrane, Proc. R. Soc. A Math. Phys. Eng. Sci. 97 (1920) 286-307. doi:10.1098/rspa.1920.0034.

[46] A. Hisyam A. Razak, P. Szabo, A.L. Skov, Enhancement of dielectric permittivity by incorporating PDMS-PEG multiblock copolymers in silicone elastomers, RSC Adv. 5 (2015) 53054-53062. doi:10.1039/C5RA09708H.

[47] S.W. Rutherford, D.D. Do, Review of time lag permeation technique as a method for characterisation of porous media and membranes, Adsorption. 3 (1997) 283-312. doi:10.1007/BF01653631.

[48] R.M. Barrer, Diffusion in and through solids, The University Press, Cambridge, England, 1941.

[49] J. Crank, The mathematics of diffusion, 2nd ed., Clarendon Press, Oxford (England), 1975.

[50] H.L. Frisch, The Time Lag in Diffusion. IV, J. Phys. Chem. 63 (1959) 1249-1252. doi:10.1021/j150578a008.

[51] H.L. Frisch, Anomalous Polymer-Penetrant Permeation, J. Chem. Phys. 37 (1962) 2408. doi:10.1063/1.1733018. 
[52] L. Masaro, X.X. Zhu, Physical models of diffusion for polymer solutions, gels and solids, Prog. Polym. Sci. 24 (1999) 731-775. doi:10.1016/S0079-6700(99)00016-7.

[53] C.M. Hansen, In defense of the diffusion equation, unpublished manuscript(available at www.hansensolubility.com) (2013)

[54] K.H. Dai, J. Washiyama, E.J. Kramer, Segregation Study of a BAB Triblock Copolymer at the A/B Homopolymer Interface, Macromolecules. 27 (1994) 4544-4553. doi:10.1021/ma00094a018.

[55] S. Srinivasan, G.H. McKinley, R.E. Cohen, Assessing the Accuracy of Contact Angle Measurements for Sessile Drops on Liquid-Repellent Surfaces, Langmuir. 27 (2011) 1358213589. doi:10.1021/la2031208.

[56] T.E. Balmer, H. Schmid, R. Stutz, E. Delamarche, B. Michel, N.D. Spencer, H. Wolf, Diffusion of Alkanethiols in PDMS and Its Implications on Microcontact Printing $(\mu \mathrm{CP})$, Langmuir. 21 (2005) 622-632. doi:10.1021/la048273l.

[57] J.F. Narváez Valderrama, K. Baek, F.J. Molina, I.J. Allan, Implications of observed PBDE diffusion coefficients in low density polyethylene and silicone rubber, Environ. Sci. Process. Impacts. 18 (2016) 87-94. doi:10.1039/C5EM00507H.

[58] T.P. Rusina, F. Smedes, J. Klanova, Diffusion coefficients of polychlorinated biphenyls and polycyclic aromatic hydrocarbons in polydimethylsiloxane and low-density polyethylene polymers, J. Appl. Polym. Sci. 116 (2010) 1803-1810. doi:10.1002/app.31704.

[59] A.N. Gent, R.H. Tobias, Diffusion and equilibrium swelling of macromolecular networks by their linear homologs, J. Polym. Sci. Polym. Phys. Ed. 20 (1982) 2317-2327. doi:10.1002/pol.1982.180201212.

[60] L. Garrido, J.E. Mark, J.L. Ackerman, R.A. Kinsey, Studies of self-diffusion of poly(dimethylsiloxane) chains in PDMS model networks by pulsed field gradient NMR, J. Polym. Sci. Part B Polym. Phys. 26 (1988) 2367-2377. doi:10.1002/polb.1988.090261113.

[61] L. Garrido, J.E. Mark, S.J. Clarson, J.A. Semlyen, Studies of cyclic and linear poly(dimethylsiloxanes). 15. Diffusion coefficients from network sorption measurements, 
Polym. Commun. 25 (1984) 218-220.

[62] A.N. Gent, S.Y. Kaang, Diffusion of linear polyisoprene molecules into polyisoprene networks, J. Polym. Sci. Part B Polym. Phys. 27 (1989) 893-911. doi:10.1002/polb.1989.090270413.

[63] A. Reynier, P. Dole, S. Humbel, A. Feigenbaum, Diffusion coefficients of additives in polymers. I. Correlation with geometric parameters, J. Appl. Polym. Sci. 82 (2001) 2422-2433. doi:10.1002/app.2093.

[64] W.C. Griffin, Hydrophile-lipophile balance and cloud points of nonionic surfactants, J. Soc. Cosmet. Chem. 5 (1954) 249-256.

[65] H. Madadi, J. Casals-Terré, Long-term behavior of nonionic surfactant-added PDMS for selfdriven microchips, Microsyst. Technol. 19 (2013) 143-150. doi:10.1007/s00542-012-1641-7. 